\title{
Cognitive theories of autism
}

\author{
Gnanathusharan Rajendran ${ }^{\mathrm{a}, *}$, Peter Mitchell ${ }^{\mathrm{b}}$
}

\section{Introduction and the history of cognitive theories of autism}

Three cognitive theories have dominated psychological research into autism. This article considers these theories by describing the research which gave life to them, studies which resulted in them being changed, and those which resulted in them being specified more clearly. The paper provides a history of each theory and so reveals how and why they have evolved. It also tackles the issues of specificity, uniqueness, and universality: (1) does autism arise from a domain-specific factor or are multiple factors involved? (2) Is the factor unique to the disorder or is it also involved in other developmental disorders? (3) Is the factor (or factors) found in every individual with autism or just in the majority? 


\section{The history of cognitive theories of autism}

Since autism was first described, independently and almost simultaneously, by Leo Kanner (1943) and Hans Asperger (1944), many theories have been proposed to account for this enigmatic condition. One infamous example is Bettleheim's (1967), now completely discredited, 'Refrigerator mother' theory. In his book, The Empty Fortress, Bettleheim stated that an emotionless parenting style caused the child to develop autism. In contrast, others theories, which did not try to explain the disorder, were nevertheless influential in developing interventions. For example, Lovaas derived techniques from operant conditioning to create behaviour therapy (e.g., Lovaas, Schaeffer, \& Simmons, 1965) and training to use language (e.g., Lovaas, 1966).

Theories of autism have tended to mirror the Zeitgeist of their times, and so with the dawn of the Cognitive Era came the search for more cognitively based explanations through experimentation. The earliest, and most influential work of this kind came from researchers such as, Frith, Prior, Rumsey, and Hermelin and O'Connor who investigated cognitive abilities including perception, memory and language (these studies from the mid-60s were reviewed by Prior, 1979).

Early perceptual research suggested that autism involved a problem in this area. However, these studies produced mixed findings of both under- and oversensitivity to both visual and auditory stimuli (e.g., Prior, Gajzago, \& Knox, 1976). Additionally, these problems were not unique to autism because they were found in children with conditions such as developmental aphasia, blindness and deafness (Wing, 1969). It also seemed from Frith's $(1970,1971)$ work that problems of perception might stem from a more primary problem in selective attention (an argument that has recently been investigated as a deficit in expanding the attentional 'window', Mann \& Walker, 2003).

At that time, memory research in children with autism suggested that their auditory memory was better than their visual memory (Hermelin \& O'Connor, 1970; Prior, 1977). However, these differences seemed dependent on the specific demand characteristics of the tasks (with children with autism performing especially well on rote memory tasks) and also on an individual's intellectual ability, rather than having autism per se. Verbal memory was also highlighted as being different in autism when Hermelin and O'Connor (1967) found that children with autism were not helped by semantic and syntactic clues. Hermelin and O'Connor (1967) found that individuals with autism were no better at recalling related sentences than random word strings. This was in comparison to typically developing individuals who showed better recall for related sentences in comparison to random word strings (see Bowler, Matthews, \& Gardiner, 1997 and Tager-Flusberg, 1991, for contemporary studies about category use to aid recall).

The centrality of disordered language in autism was also highlighted in early research (and, like investigations of perception in autism, is regaining favour). Early language work in autism was more descriptive because little was known about how language development related to perception and cognition. Broadly speaking, however, children with autism were subcategorised into children with autism who acquired language spontaneously, those who acquired language in a delayed or deviant fashion (Ricks \& Wing, 1976), and those who did not acquire language at all.

However, it was only in the mid-80s that a theory proposed that some of the core elements of autism might arise from a primary cognitive deficit. In doing so, the theory 
imposed a developmental psychological perspective on research and became hugely influential for both researchers and practitioners.

\section{The Theory of Mind Hypothesis of autism}

In essence, this theory states that individuals with autism fail to "impute mental states to themselves and others" (Premack \& Woodruff, 1978, p. 515) and that this deficit manifests as inability to mentalise, or failure to take into account others' mental states. The most widely used test of Theory of Mind is the unexpected transfer test of false belief, which was devised by Wimmer and Perner (1983). In the task the participant watches a sequence of events, usually enacted by dolls. The story unfolds so that one doll has a belief about the location of an object that is incongruous with its real location. The participant then makes a judgement about where the doll will look, and in order to give the correct answer the participant has to infer the mental state of the doll (I think he thinks). Baron-Cohen, Leslie, and Frith (1985) found that 80 percent (16/20) of children with autism failed the unexpected transfer task and concluded that these children had a deficit in their theory of mind. These seminal results have been widely replicated with that task as well as other tests of false belief, such as the deceptive box (Perner, Frith, Leslie, \& Leekam, 1989).

Happé (1994), however, stated that it was problematical for the Theory of Mind Hypothesis that 20 percent of autistic individuals actually passed tests of false belief, and so the deficit seemed not to be universal. There are at least three ways of explaining this: (1) passing a test of false belief requires multiple skills and although some individuals pass the test, they do so in a way that is very different from that of individuals without autism; if so, then passing or failing a test is not as important or revealing as the way in which the participant goes about tackling the test. (2) The diametrically opposed position is that being able to pass a test of false belief is only possible for anyone who has a representational theory of mind; if this line of argument is followed, then the Theory of Mind Hypothesis of autism is untenable because it cannot account for the possibility that some individuals pass tasks when autism is identified as an impairment in theory of mind. (3) In between these two positions, it could be argued that the Theory of Mind Hypothesis may explain some of the cognitive impairments seen in autism, but that it does not fully explain all facets of the disorder.

In the face of the issue of universality, Baron-Cohen modified his theory by proposing that a theory of mind problem was in fact a delay rather than a deficit. To investigate this, Baron-Cohen (1989) used the more difficult second-order false belief task (I think he thinks she thinks), once again borrowing from a paradigm first developed by Perner and Wimmer (1985). Baron-Cohen (1989) found that 90 percent of typically developing children (mean chronological age 7.5) passed the test, as did 60 percent of the children with Down syndrome (mean verbal mental age of 7.5), but none of the children with autism passed (Mean verbal mental age of 12.2). Baron-Cohen concluded that although some individuals with autism may be capable of passing a first-order theory of mind task, they could not pass a second-order task and therefore did not have a fully representational theory of mind.

Subsequently, a study by Bowler (1992) challenged the idea that theory of mind development is delayed in autism. He found that 73 percent of young adults with Asperger syndrome (AS) passed the second-order false belief task, which left a quandary: how could autism be explained as impairment in theory of mind when some individuals with an autistic profile managed to pass both first and second-order tasks? The finding that both first 
and second levels of belief attribution were being achieved by a subset of individuals with autism, was enough to convince some researchers (e.g., Ozonoff, Pennington, \& Rogers, 1991a; Ozonoff, Rogers, \& Pennington, 1991b) that Theory of Mind Deficits were not universal in autism.

The developmental delay argument was supported, though, in a meta analysis by Happé (1995) which showed a strong association between verbal mental age and false belief task performance in children with autism. Happé discovered that the probability of passing a false belief task was highly predicted by verbal mental age: participants with a verbal mental age of 12 and above were almost certain to be able to pass. The timing of this success represents a huge delay compared to typically developing children, who succeed at a calendar age of about four (Wellman, Cross, \& Watson, 2001).

Given that verbal mental age is related with task performance to such a high degree, belief attribution tasks can tell us little about the impairments of higher-functioning autistic individuals who would undoubtedly perform at ceiling. Researchers, therefore, designed advanced tests of theory of mind specially for this population, including: the Eyes Test (Baron-Cohen, Jolliffe, Mortimore, \& Robertson, 1997; Baron-Cohen, Wheelwright, Hill, Raste, \& Plumb, 2001a; Baron-Cohen, Wheelwright, Scahill, Lawson, \& Spong, 2001b), the Recognition of Faux Pas Test (Baron-Cohen, O’Riordan, Stone, Jones, \& Plaisted, 1999), and the Strange Stories test (Happé, 1994; Jolliffe \& Baron-Cohen, 1999a). These tests shifted away from Wimmer and Perner's tasks and moved into the different territory of language and face processing in autism.

\section{The Strange Stories test}

Historically, the first of these advanced tests was developed by Happé (1994) who created 24 stories to provide a more naturalistic challenge to individuals with autism. She designed the stories to be simple accounts of everyday events about different motivations that lay behind utterances that are not literally true. Happé gave the example of lying to someone when they ask you about their new dress. It may look awful, but you might say it looks good in order to spare their feelings or mischievously, to mislead them into wearing it.

Happé (1994) presented autistic participants with 24 short vignettes, about everyday situations, in which people say things they do not mean literally. The stories were each accompanied by a picture and usually two test questions: a comprehension question "Was it true, what X said?" and a justification question, "Why did X say that?". Mental state justifications, given in response to the why question (e.g., "because Emma is pretending the banana is a telephone"), provided the evidence for having a theory of mind. Happé found that varying degrees of success on the Strange Stories could discriminate between individuals with autism who failed theory of mind tasks, individuals who passed first-order order theory of mind tasks and those who passed second-order theory of mind tasks. Importantly, even individuals with autism who passed second-order theory of mind tests gave incorrect mental state justifications for some of the stories, unlike the neurotypical adult participants who made no such errors.

Jolliffe and Baron-Cohen (1999a) conducted a replication of Happé's (1994) study with two adult autistic groups: one comprised individuals with Asperger syndrome (AS), the other high-functioning individuals with autism (HFA). Jolliffe and Baron-Cohen found that both clinical groups failed to use context-appropriate mental state terms to explain the 
strange stories, and in this respect, they differed from comparison participants. Jolliffe and Baron-Cohen's results showed that even at the very highest functioning end of the autistic spectrum (including those without any early language delay, i.e. those with AS) had difficulty comprehending nonliteral language.

\section{The Eyes Task}

After the creation of the Strange Stories Test the next most influential advanced test of theory of mind was arguably the "Reading the Mind in the Eyes Task", or Eyes Task for short (Baron-Cohen et al., 1997). Baron-Cohen et al. (1997, 2001a, 2001b) showed participants photographs of the eye region of people's faces (from midway along the nose to just above the eyebrow). Baron-Cohen et al. (1997) then asked an adult group with AS/HFA, an adult group with Tourette syndrome and a normal adult group if they could infer the mental states of the people by looking at photographs of their eye region. By way of response, participants were invited to select one of four adjectival choices.

Notably, the adults with autism performed significantly less well than comparison groups (i.e., gave fewer accurate responses). In the control Emotion Task, participants had to judge photographs of whole faces displaying basic emotions (happy, sad, angry, afraid, disgusted, and surprised). The group of individuals with autism performed at ceiling and so the experimenters ruled out any deficits in understanding basic emotional expressions as an explanation for poor performance on the Eyes Task. Baron-Cohen et al. (1997) argued that the Eyes task provides a 'pure' test of theory of mind and moreover that the results support the possibility that individuals with autism have a specific impairment in reading mentalistic information from the region of the eyes.

A recent study by Back, Ropar, and Mitchell (in press) challenges the claim that individuals with autism have difficulty imputing mental states specifically because they are impaired in reading information from the eyes. In the study, participants viewed dynamic faces posing expressions associated with mental states. Although participants with ASD performed well above chance in selecting the correct mental state term from a choice of four alternatives, they were slightly inferior to participants without autism. The sophisticated digital editing used in the study allowed facial regions to be frozen, such that they were neutral and uninformative. Importantly, when the eyes were frozen, the performance of those with autism deteriorated at least to the same degree as participants without autism. This was a surprising finding because if participants with autism were impaired in interpreting information from the eyes, then freezing that facial region should not cause much if any deterioration in performance. The finding that participants with autism were significantly worse at recognizing mental states from faces with frozen eyes suggests that when the eyes were dynamic and informative they were reading information from this region, contrary to Baron-Cohen et al.'s (1997) claims.

Rutherford, Baron-Cohen, and Wheelwright (2002) and Golan, Baron-Cohen, Hill and Rutherford (in press) extended mind reading tests into the auditory domain, by asking autistic participants to extract mental state information from vocalizations. In the Reading the Mind in the Voice test, participants heard a 2-s sample of audio dialogue and had to choose between two adjectives to best describe the mental state of the speaker. Rutherford et al. found that the participants with AS/HFA gave fewer correct answers than two adult control groups, suggesting difficulties drawing inferences about mental states from speech. 
Baron-Cohen et al. (1999) stated that passing first and second-order tests of false belief should be seen as an early accomplishment in acquiring a theory of mind and not an end point. Specifically, they argued that theory of mind deficits remain undetected in higherfunctioning autistic individuals if only first and second-order false belief tests are used. Implicit in this line of argument is that an advanced theory of mind task requires more of an amount of theory of mind (compared with belief attribution tasks). It is as though theory of mind had become a quantifiable entity that a person could have more or less of, and that you need to reach a certain threshold of theory of mind in order to pass a developmentally appropriate task. This is a shift away from the original conception of theory of mind as either being absent or present in an absolute sense.

\section{Principled problems with Advanced Theory of Mind tests}

Wimmer and Perner (1983) devised their test of false belief following an analysis of the evidence needed in order to credit a person with a fully fledged representational theory of mind. At the outset, it was an open question regarding what age an individual would show such evidence, and the test was not developed a priori for a specific age group. Many studies have subsequently found that the majority of children pass the unexpected transfer false belief task when they are about 4 years old (Wellman et al., 2001). Hence, it seems that the development of Advanced Theory of Mind tests began (along with the suggestion that understanding the mind continues to develop beyond the fifth year in typical development) only with the discovery that some individuals with autism pass both first and second-order theory of mind tasks. In other words, the development of advanced tests could be viewed as a post hoc response in finding data anomalous to the theory of mind hypothesis that some individuals with autism pass tests of false belief. In Baron-Cohen et al.'s (1985) seminal study, the aim was to use what was regarded as a definitive test of theory of mind (i.e., an unexpected transfer test of false belief) to discover whether or not individuals with autism have an impaired theory of mind. Subsequent studies using advanced tests have turned this logic on its head: they seem to be premised on the assumption that individuals with autism do have an impaired theory of mind, implying that tests which do not reveal this must be insensitive or unsuitable.

Advanced tasks lack an ingredient that Dennett (1978) identified as being essential for diagnosing a representational theory of mind. In the unexpected transfer task, for example, there is a certain causal relation between information and knowledge: Sally saw the marble in Location 1, which caused her to believe it existed there; she did not see it being moved subsequently to Location 2, and so we might suppose that there is no cause, at least in informational terms, for her belief to change - by default, she would still believe the marble was in Location 1. Advanced tests of theory of mind seem not to be based around the principle that it is vital to test a person's understanding of the causal relation between informational access and the consequent state of belief. Researchers have arguably been able to free themselves from the requirement for this causal relation in theory of mind tasks by changing the name to mindblindness (e.g., Baron-Cohen, Golan, Wheelwright, \& Hill, 2004; Golan \& Baron-Cohen, 2006). Consequently autism is understood as a condition of mindblindness, rather than a deficit in theory of mind.

Furthermore, groups of autistic individuals tend to do less well relative to comparison groups on advanced tests, but they do not show outright failure (e.g., Baron-Cohen et al., 1997). Therefore, results are not ideal for arguing that individuals with autism are devoid of a theory of mind and as such they are problematic for a domain-specific modular 
account of autism (Baron-Cohen, 1995). This problem with the account has wider ramifications considering that evidence for a domain-specific deficit in theory of mind has been seen by some as support for modular theory (Fodor, 1992; Leslie \& Thaiss, 1992) and for the existence of different domains of core knowledge (e.g., biology, physics, psychologysee Carey, 1985).

\section{How else could you pass a Theory of Mind Task}

Frith, Happé, and Siddons (1994) suggested that autistic passers of both first and second-order theory of mind tasks might have used non-theory of mind and non-mentalistic methods to solve the tasks by "hacking" out solutions. Although Frith et al. (1994) do not define hacking, they seem to be implying that the individuals with autism who pass do not infer the mental states of the protagonists in a false belief story, but instead use a method of hacking to achieve the correct answer, as if it were purely a logical problem.

Arguably, a clearer distinction needs to be made between theory of mind and the 'litmus-tests' of theory of mind: the various tests of false belief. Using the terms 'theory of mind' and 'false belief' synonymously causes confusion. Moreover, the wide-spread use of the unexpected transfer task on its own, as a measure of theory of mind, has been called into question (Marschark, Green, Hindmarsh, \& Walker, 2000; Russell et al., 1998), and some authors (Bloom \& German, 2000) have gone as far as arguing that it should be abandoned as a test of theory of mind altogether.

\section{A reconceptualisation of Theory of Mind? The enactive mind}

Because the definition of theory of mind was left open, there has been much debate as to what it actually is. Some researchers conceptualise theory of mind as a folk theory (e.g., Wellman, 1990), while others think of it as a cognitive module (Baron-Cohen, 1995), while still others believe it is social problem-solving (Peterson \& Bowler, 2000). The debate has been brought into sharper focus with the advent of the theory of mind deficit account of autism because not only does this give insight into the potential origins of mentalistic understanding, it also has implications for the nature of interventions. If others' mental states are apprehended by working through a rule-bound algorithm (Wimmer, Hogrefe, \& Perner, 1988), then perhaps these rules could be taught (Hadwin, BaronCohen, Howlin, \& Hill, 1996, 1997). However, there is no evidence of the success of this approach in terms of the individual generalising from how to pass an unexpected transfer task to their everyday social cognition: children "may have learned to pass the tasks rather than understand the concepts underlying the rules" (Hadwin et al., 1996, p. 359).

A recent reconceptualisation of Theory of Mind has arguably been the Enactive Mind hypothesis (Klin, Jones, Schultz, \& Volkmar, 2003). Klin et al. argue that from the very outset the autistic mind is not attuned to the social world; for example, the gaze and gaze following patterns of individuals with autism are different from neurotypicals and most notably the eye region does not capture attention as strongly in those with autism. In stark contrast the neurotypical mind seems to be constantly prepared to interpret social

\footnotetext{
1 The use of a non-mentalistic algorithm has been computer modelled (Wahl \& Spada, 2000). Modelling firstand second-order belief attribution tasks allowed them to accurately predict children's performance on these tasks.
} 
meaning, and arguably overextends this capacity to find social meaning even amongst nonliving entities.

Klin began to construct his arguments from a Social Attribution Task; in it he (Klin, 2000) showed a group of higher-functioning adolescents and adults with autism, a group with AS and neurotypicals Heider and Simmel's (1944) silent animation of geometric objects interacting with each other. Klin asked participants to describe the animation and analysed their narratives. The participants with HFA and AS tended to describe the animation in mainly geometric terms, whereas the neurotypical control group searched for social meaning. For example, one neurotypical said:

"What happened was that the larger triangle - which was like a bigger kid or bully - had isolated himself from everything else until two new kids come along and the little one was a bit more shy, scared, and the smaller triangle more like stood up for himself and protected the little one..." (Klin, 2000, p. 840).

In contrast one adolescent with autism, whose verbal IQ was similar to the neurotypical child above said:

"The big triangle went into the rectangle. There were a small triangle and a circle. The big triangle went out. The shapes bounce off each other. The small circle went inside the rectangle. The big triangle was in the box with the circle. The small triangle and the circle went around each other a few times..." (Klin, 2000, p. 840).

Hence, Klin's results suggest that typically developing people look for social meaning, even in the relation between geometric shapes. This contrasts with individuals with autism who report relations purely in terms of their physical properties.

\section{Summary}

Although the research output from theory of mind/belief attribution studies is waning (both in typically and atypically developing populations), the legacy of this theory, especially in autism, is both undeniable and irrepressible; the essential clinical picture that individuals with autism have difficulties understanding both their own and others' mind seems unquestionable. However, its definition and its theoretical underpinning have yet to be agreed upon, even after 20 years of research. In historical terms, the Theory of Mind Hypothesis of autism brought developmental psychologists into mainstream autism research.

\section{Theory of Executive Dysfunction in autism}

Perhaps the most important difference between the theory of mind hypothesis and EF accounts of autism is that executive functions are intrinsically domain-general, whereas the theory of mind hypothesis posits a domain-specific deficit.

\section{Symptomatology}

In contrast to the theory of mind hypothesis of autism, the Executive Function (EF) account was not born from neurotypical research; rather, its conception came from researchers who noted that some symptoms of autism were similar to those associated with specific brain injury. Moreover, these symptoms were not easily explained by the theory of mind account. For example, a need for sameness, a difficulty switching attention, a 
tendency to perseverate and a lack of impulse control are symptoms similar to those shown by individuals with what is now known as Dysexecutive Syndrome (DES, Baddeley \& Wilson, 1988). Such individuals have problems with executive function usually, but not exclusively, due to frontal lobe damage. This led some researchers (e.g., Ozonoff et al., 1991a) to suggest that autism could be explained as deficit in EF.

Historically, the notion of EF comes from the analysis of the resultant damage to the Prefrontal Cortex (PFC). Recently, however, EF studies have been carried out by researchers of typical and atypical cognitive development (Zelazo \& Müller, 2002). Despite EF being traditionally related to the PFC, EF is not the same as PFC function. For example, Shallice and Burgess (1991) found that some individuals with PFC damage did not show impairments in EF, while some people with damage outside the PFC do show impairments (e.g., Anderson, Damasio, Jones, \& Tranel, 1991; Levisohn, Cronin-Golomb, \& Schmahmann, 2000). Interestingly, the PFC is also thought by some to be a site of theory of mind abilities (Shallice, 2001; Stone, Baron-Cohen, \& Knight, 1998; Stuss, Gallup, \& Alexander, 2001) and, thus, hints at a shared brain site for these functions (see Apperly, Samson, \& Humphreys, 2005, for an overview).

\section{Defining executive function}

In contrast to theory of mind, it has been easier to define EF. This is because EF is an umbrella term for functions including: initiating, sustaining, shifting and inhibition/stopping (Denkla, 1996a). Denkla (1996b) argues that although EF may be relevant to metacognitive processes, it ought to remain close to its clinical neurology roots of motor praxis or 'execution' in, for example, motor sequencing tasks. Ozonoff et al. (1991a) provide a more extensive definition:

"Executive function is defined as the ability to maintain an appropriate problem-solving set for attainment of a future goal; it includes behaviors such as planning, impulse control, inhibition of prepotent but irrelevant responses, set maintenance, organized search, and flexibility of thought and action" (p. 1083).

Zelazo and Müller (2002) highlight that definitions of executive functions are often lists and accordingly Tranel, Anderson, and Benton (1994) suggested that EF corresponds to: planning, decision-making, judgement and self perception. In contrast, Gillberg and Coleman (2000) define EF as all those faculties needed to work in a motivated fashion, towards a goal that may not be reached instantly.

Because EF is so broadly defined, Zelazo, Carter, Reznick, and Frye (1997) have used Luria's (1973) idea that EF is a function, an operation, which captures the diversity of executive processes without listing them or locating them in a homunculus. Zelazo et al. posit a problem solving role for EF, stating that EF is a function and neither a mechanism nor a cognitive structure. They argue that functions are behavioural constructs defined by their outcome, and the outcome of the use of executive abilities is rightly defined in terms of problem solving.

\section{Ecological validity in executive function tasks}

In their investigation of ecological validity, Burgess, Alderman, Evans, Emslie, and Wilson's (1998) factor analysis revealed that EF tasks assessed either one of three aspects: Inhibition, Intentionality, and Executive Memory. 
Inhibition tests are those in which the participant has to inhibit a prepotent response, as with the Stroop test (Stroop, 1935). In this test the interfering influence of one input modality can be measured on the performance of another modality (e.g., naming the ink colour of colour words when the word and ink are either congruent - the word 'green' printed in green ink - or incongruent - the word 'green' printed in red ink). Inhibition, in this sense, might be considered the ability to suppress a habitual response.

Intentionality tests involve an ability to handle embedded rules, which Frye, Zelazo, and Palfai (1995) argue is relevant to making judgments of false belief. These tests require the participant to adhere to multiple layers of rules and include Modified Six Elements, Zoo Map, Key Search and Action Programme tests from the Behavioural Assessment of the Dysexecutive syndrome (BADS, Wilson, Alderman, Burgess, Emslie, \& Evans, 1996) and the Tower of London (Shallice, 1982). Intentionality is the ability to create and maintain goal-directed behaviours. For example in the unexpected transfer task, the participants first have to suppress a prepotent but incorrect response, and they must retain action-relevant information in working memory while doing so. According to Russell (1996), intentionality is the precursor of self-awareness, and is relevant to developing a grasp of agency, coupled with mental state concepts.

In tests of Executive Memory, participants have to shift attention between stimuli/ response sets. In most tests, participants must shift from a dominant response according to an arbitrary rule, for example, Rule Shift Cards (BADS, Wilson et al., 1996), Wisconsin Card Sorting Task (WCST, Heaton, 1981). In the Rule Shift Cards, the participant has to respond 'Yes' or 'No' when a series of 20 playing cards are turned over one at time. In the first version of the task the participant has to use the rule, 'say yes to red and no to black', and in the second version the participant must use the rule, 'say yes if the card is the same colour as the last one, otherwise say no.'

Inhibition, Intentionality and Executive Memory are Burgess et al.'s labels for the factors, but there is no wider consensus about these labels. Additionally, the emergence of these three factors is dependent on the tests included in the factor analysis, and it seems likely that these tests probably load to some degree on multiple factors. For example, in the BADS test, some of the subtests have multiple components: planning, problem solving and monitoring behaviour are required for the Zoo Map and Modified Six Elements (Norris \& Tate, 2000).

\section{Universality in executive problems}

According to Liss et al. (2001), one problem in determining the prevalence of executive deficits in autism is that most studies focus on group differences, without reporting individual variations. To our knowledge only three studies do this. Ozonoff et al. (1991a) found that 96 percent of the autistic group performed less well on EF tests than the control group mean (this is arguably a very liberal criterion). In contrast Pellicano, Maybery, Durkin, and Maley (2006) reported that executive problems were only found in 50 percent of their sample. Consistent reporting of proportions, like those seen in Ozonoff et al.'s (1991a, 1991b) and Pellicano et al.'s studies, would help in determining the universality of EF deficits in autism.

\section{Uniqueness of executive problems or the 'discriminant validity' problem}

Individuals with Attention Deficit Hyperactivity Disorder (ADHD), Schizophrenia, Obsessive Compulsive Disorder and Tourette syndrome perform similarly to autistic 
individuals on some tests of executive function. It seems, therefore, that executive deficits in themselves are not unique to autism. Ozonoff (1997) concluded that unlike the disorders listed above, autism involves a specific deficit in cognitive flexibility, while inhibition remains relatively less affected or even spared. ${ }^{2}$ Evidence for this comes from Ozonoff and Jensen (1999) who found, in a study comprising children with autism, Tourette syndrome and ADHD, that the autistic children had problems in task flexibility whereas the ADHD children had problems of inhibition. However, some studies have been unable to differentiate different disorders; for example, Nyden, Gillberg, Hjelmquist, and Heiman (1999) failed to discriminate between boys with attention deficit disorder, writing disorder and AS in terms of their executive profiles. Therefore, studies trying to differentiate disorders on the basis of performance on EF tasks have yielded mixed and inconsistent results.

In reviewing the EF autism literature, Hill (2004a, 2004b) divided the studies into categories of EF: planning, mental/cognitive flexibility (set shifting), inhibition, generativity and self-monitoring. Hill's review suggests that evidence for a unique deficit in autism in one of these functions seems unlikely. However, it may still be that a distinct EF profile distinguishes autism from other neurodevelopmental disorders. The search for such a profile will be a key aim in the coming years.

Differentiating between disorders, on the basis of EF, is not made any easier because of the difficulty in isolating the specific form of EF impairment; probably because although EF tests have been designed to investigate only one aspect of EF (see Burgess et al., 1998), they in fact often measure multiple executive abilities. Hence, a key challenge facing EF research lies is in designing tests and studies that measure one aspect of EF in isolation. For example, the frequently used WCST is interpreted as examining cognitive flexibility through set shifting; this has been thought to tap into just one executive process, but in fact it may draw upon more (see Zelazo, Burack, Boseovski, Jacques, \& Frye, 2001).

\section{Inconsistency in results between studies of EF}

In addition to identifying problems associated with uniqueness, Hill's review (2004a) and experiment/review (Hill \& Bird, 2006) highlights that studies of EF in autism have not been consistent in their findings, and researchers have sometimes failed to replicate results of others even when using identical tasks and methodologies (see Pennington \& Ozonoff, 1996, for an earlier review).

In planning ability, assessed by Tower tasks (e.g., Tower of Hannoi, Tower of London), studies have consistently found planning impairments in children and adults with autism (Bennetto, Pennington, \& Rogers, 1996; Ozonoff \& Jensen, 1999; Ozonoff \& McEvoy, 1994; Ozonoff et al., 1991a, 1991b). Mari, Castiello, Marks, Marraffa, and Prior (2003) found that planning ability, however, was related to IQ rather than autism per se in a kinematic reach-to-grasp task.

For tasks of mental flexibility (set shifting), 9 out 14 studies cited in Hill (2004a) found impairments in participants with autism in this ability when using the WCST. Once again, however, negative results were found in those studies in which IQ (especially verbal IQ) was found to play a mediating role in performance.

\footnotetext{
${ }^{2}$ N.B., Ozonoff (1997) states that EF tasks (e.g., WCST) often conflate different executive abilities including cognitive flexibility and inhibition, but when an information processing approach is taken, these processes can be teased apart.
} 
For inhibition tasks, performance seems to be consistently related to task demands because individuals with autism display similar problems of interference as controls in two studies investigating the Stroop effect (Eskes, Bryson, \& McCormick, 1990; Ozonoff \& Jensen, 1999). However, the Windows task in all its incarnations (e.g., Russell, Mauthner, Sharpe, \& Tidswell, 1991, see below) has consistently found that individuals with autism have problems inhibiting prepotent responses.

Generativity studies have provided mixed results with a couple of letter/word fluency studies finding an impairment in individuals with autism (Rumsey \& Hamburger, 1988; Turner, 1999) and a couple of letter/verbal fluency experiments showing no impairment in this population (Minshew, Goldstein, \& Siegel, 1995; Scott \& Baron-Cohen, 1996).

Self-monitoring tasks tap into the ability to monitor one's own thoughts and actions and to adjust one's behaviour accordingly. An example is the automated version of the Window's Task (see below), in which some level of self-monitoring of one's goal directed behaviour is required for success. Self-monitoring studies have provided inconsistent results, with those specifically looking at self-monitoring failing to find any difference between individuals with an without autism (e.g., Hill \& Russell, 2002; Russell \& Hill, 2001). In contrast, studies that were not devised directly to investigate self-monitoring, but that have self-monitoring aspects have found self-monitoring deficits (e.g., error correction and avoidance in Russell \& Jarrold, 1998). To date, only one published study has investigated multitasking in autism and its results point to a deficit in the disorder (Mackinlay, Charman, \& Karmiloff-Smith, 2006).

In sum, it seems that the EF hypothesis can explain many of the features of autism. However, its limitations are that not all individuals with autism show executive problems and those who do may have differing profiles of EF. Moreover, executive difficulties are not unique to autism and are seen in other disorders. A further issue is that some researchers have argued that executive abilities may be related to theory of mind. Others have countered this argument by saying that executive abilities are needed for theory of mind. The relation between the two is discussed below.

\section{How might executive function deficits relate to deficits in Theory of Mind?}

Russell and colleagues (Hala \& Russell, 2001; Russell, Hala, \& Hill, 2003; Russell et al., 1991) devised an EF task that includes elements of deception, and hence theory of mind. In their standard 'Windows Task', a child had to learn to inhibit their prepotent response to point to chocolate located in one of two boxes. In order to win the chocolate the child had to point to the empty box, rather than to the box baited with chocolate. Children with autism and typically developing 3-year olds behaved in much the same way in the task; that is, they seemed unable to resist pointing to the box that contained the treat, resulting in their adult opponent repeatedly winning the treat by default. In contrast, typically developing 4-year olds and children with Down syndrome were able to resist the urge to respond impulsively and so were able to point to the empty box and win the chocolate for themselves.

Russell et al. (1991) argued that 3-year olds and children with autism fail the unexpected transfer task not because they fail to take account of Sally's mental state, but because they act impulsively in relation to the location of the marble. The Windows Task neatly links executive function with theory of mind because the participants must (i) curb the impulse (executive control) to point directly at what they want and (ii) be deceptive because the 
other player acts on the participant's gesture (if the other player does not find the chocolate, it is available for the participant to collect).

A criticism of the original Windows Task was that it was socially embedded in that the child had to competitive with the other adult player. In response, Russell et al. (2003) created an automatic version of the task in which children had to retrieve a marble in a box, either by turning a knob or flicking a switch on the side of the box. Even with the competitive social element removed, children with autism still had problems of inhibition.

\section{Cognitive Complexity and Control theory}

An alternative approach to understanding EF in autism is Cognitive Complexity and Control theory (CCC, Frye et al., 1995; Zelazo \& Frye, 1997). CCC is a hybrid theory that states that EF is related to theory of mind in typical and atypical individuals because both theory of mind and measures of executive ability involve higher order rule use. For example, a correct answer in the unexpected transfer task requires the use of higher order rules to make a correct judgement about where a doll will look: one might say, "I know that the object is in location B, but if I am asked about the doll, and if the question asks where will the doll look for the object, then the answer is location A."

CCC theory offers an alternative to the 'either-or' argument, that is, whether executive abilities are required to perform well on theory of mind tasks or vice versa. Additionally, Zelazo et al. (2001) make three points in arguing that CCC framework is useful in understanding developmental disorders. First, they argue that any kind of developmental disorder may impact on consciousness, rule-complexity and behavioural control. In this context, it is notable that theories of autism have largely ignored the fact that a significant number of individuals with autism are intellectually impaired (i.e., with IQs under 70). Zelazo et al. (2001) argue that although intellectual impairment is not unique to autism, its prevalence still requires explanation. It may be that although intellectual impairment is not intrinsic, it might interact with other aspects of autism to produce the kind of results seen in both EF and theory of mind studies.

Second, CCC theory allows researchers to determine what makes different disorders unique from each other. For example, using the problem-solving framework for executive function, EF tasks can be broken down into their constituent components enabling success or failure to be explained more specifically. Therefore, rather than saying that autism is a disorder of executive function, one may be able to specify the deficits of executive function that are associated with autism (if any).

Third, CCC allows performance on different tasks from different domains to be equated, and so provides a test of specificity and uniqueness. For example, Zelazo, Burack, Benedetto, and Frye (1996) found that children with Down syndrome failed theory of mind tasks and performed poorly on a task they created called the dimensional change card sort (DCCS). In the DCCS children are asked to sort target cards into a tray according to one dimension (e.g., for colour, they are told to "Put the blue ones here and put the red ones there"). After sorting several cards the rules are changed and children are asked to switch to sorting by shape ("Put the flowers in there and put the boats in there"). Irrespective of what dimension is presented first, typically developing 3-year olds and children with Down syndrome (mean MA 5.1 years) continued to sort by the previous dimension, despite being told the new rules on every trial and having sorted cards by the new dimensions at another time. Furthermore, Zelazo et al. (2001) argue that because performance on theory of mind 
tasks and DCCS was correlated, theory of mind tasks are not domain-independent and are therefore not specific.

Zelazo, Jacques, Burack, and Frye (2002) found evidence to support CCC theory in an autistic sample. They discovered that individual differences in theory of mind were correlated with individual differences on two tests of rule use (including the DCCS) in children with autism. This relation held true for all the participants who were mildly impaired (VIQ $>40$ but $<70$ ), but not for children with autism who were severely impaired $(\mathrm{VIQ} \leqslant 40)$. Zelazo et al.'s study attracted criticism for its relatively small sample size ( $n=10$ for the mildly impaired group), and for lacking a comparison group. However, Colvert, Custance, and Swettenham (2002) essentially replicated Zelazo et al.'s study and findings with sample of 20 high-functioning children with autism, and included two neurotypical comparison groups.

\section{Summary}

O’Neill and Jones (1997) counsel against attempts to systematically investigate one aspect of autism in isolation, because such an approach does not reflect the complexity and multi-dimensionality of human behaviour. Hence, one of the strengths of the EF hypothesis is that it can account for many of the non-social aspects of autism, and it is the only theory that acknowledges both the cognitive and motor (repetitive hand flapping, rocking) characteristics of autism. However, the EF theory is also not free from criticism regarding issues of specificity, uniqueness and universality.

Arguably, the biggest problem for the theory of executive dysfunction is that because EF is multifaceted it is hard to delineate, to create tests that only measure one aspect in isolation. Additionally, EF could be viewed as a process (Zelazo et al., 2001), or it could be defined statistically by determining which EF components load onto various EF tasks (Burgess et al., 1998). There is also a debate as to whether theory of mind tasks could be reduced to executive processes (e.g., Russell et al., 1991), or whether a theory of mind is required for executive control (e.g., Perner, Lang, \& Kloo, 2002). The debate may be moving towards a resolution in that Pellicano (in press) found evidence to support Russell's but not Perner's position: some children with autism failed theory of mind tasks, but performed well on EF tasks, while no children had the opposite profile. Putting this issue aside, it may even be that the EF account's most important contribution has yet to be fully realised, in bridging the gap between accounts of developmental and acquired brain pathologies.

\section{Weak Central Coherence theory}

Weak Central Coherence Theory (WCC, Frith, 1989, 2003; Frith \& Happé, 1994; Happé, 1999) is a domain general process, and one of its key strengths is that it explains some of the non-social, as well as the social features of autism, such as the attention to acute detail that ranges from pedantry to obsession. The essence of the theory is that typically developing individuals process information by extracting overall meaning or gist. Frith and Happé suggest autism is characterized by weak or absent drive for global coherence. That is, individuals with autism process things in a detail-focused or piecemeal wayprocessing the constituent parts, rather than the global whole.

WCC theory has reinvigorated research into the perceptual abilities of individuals with autism, first pioneered by Hermelin and O'Connor in the 1960s (see Happé, 1999, for a 
review of WCC, and Happé \& Frith, 2006, for a review plus refinements to the theory; see Rogers \& Ozonoff, 2005, for a review of sensory dysfunction in autism). However, the field is far from clear due to several different interpretations of the theory.

\section{Visuospatial constructional coherence}

\section{Embedded figure and block design tasks}

The initial work on central coherence focussed on perceptual processes (see Mitchell \& Ropar, 2004, for a review of the autism visuospatial literature). Evidence came from studies (Shah \& Frith, 1983) showing that children with autism scored above average on the Children's Embedded Figures Test (CEFT, Witkin, Oltman, Raskin, \& Karp, 1971) and were better than chronologically and mental age matched typically developing children. In the CEFT participants are asked to locate a small target shape in a drawing of a larger everyday shape composed of potentially confusing lines (e.g., finding a triangle shape in a picture of a pram). When looking at the figures it seems as if the larger shapes are so captivating that the smaller embedded shape is hard to detect.

Shah and Frith (1993) also found that participants with autism were faster at reproducing 40 different block designs than learning disabled and neurotypical controls. The Block Design is a subtest of the Wechsler Intelligence Scales (e.g., WASI, Wechsler, 1999) in which the participant is asked to assemble an identical image of a 2-D picture, as fast as possible, using painted blocks of red and white. When the pictures were pre-segmented the controls' performance improved to a point where the group with autism was no longer superior. Shah and Frith suggested that participants with autism perceptually segmented the designs, such that presenting the designs pre-segmented provided no further benefit.

The key features of both the Block Design Test and the Embedded Figures Test is that a figure can be segmented or include smaller constituent components; due to the drive for central coherence in the neurotypical population, the salience of these smaller components is not as great as the global figure. Frith $(1989,2003)$ argues that individuals with autism show better performance on these tasks because they lack a cognitive drive to attend to global form; that is, they have weak central coherence.

\section{Visual illusions}

Additional support for WCC in autism was sought from suspected peaks in visuospatial and perceptual functioning. In this context, Happé (1996) made a prediction about the lack of susceptibility to visual illusions, arguing that the reason people succumb to visual illusions is because they integratively process all of the parts of an illusion. In the example of the Titchener illusion, where two comparison circles are physically identical in size, the presence of surrounding larger or smaller circles induces the misperception that the comparison circles are different in size. Happé (1996) found that participants with autism were less likely to succumb to visual illusions (e.g., Ponzo, Muller-lyer, Titchener) than other groups, arguing that individuals with autism processed parts of illusions in a piecemeal manner without integrating the comparison features with the inducing context.

However, Ropar and Mitchell $(1999,2001)$ discovered, in contrast to Happé (1996), that participants with autism were just as susceptible to visual illusions as controls. Ropar and Mitchell presented a variety of visual illusions to individuals with autism on a computer screen, and rather than asking if target elements were the same size or different they asked participants to use computer keys to adjust stimuli to be the same size. The degree to which 
participants systematically erred on the task served as a measure of susceptibility. Surprisingly, participants with autism were susceptible to the illusions to the same degree as participants without autism. Milne et al. (2002) argue that findings like those of Ropar and Mitchell $(1999,2001)$ suggest global processing seems to be under attentional control in autism and that care needs to be taken before concluding that autistic individuals have a low-level perceptual deficit (Milne et al., 2002). Another explanation is that higher-order processing is merely optional in autism but mandatory in people without autism (Mottron, Dawson, Soulieres, Hubert, \& Burack, 2006), raising the possibility that whether or not higher-order processing is triggered depends on the wording of the question. In support, Brosnan, Scott, Fox, and Pye (2004) reported that individuals with autism succumb to visual illusions (e.g., the Muller-Lyer illusion) when asked "which line looks longer", but not when asked "which line is longer."

\section{Reduced generalization}

As an alternative to WCC, Plaisted (2001) argues that perceptual processes in autism are better explained in terms of reduced generalization. Plaisted states that superior autistic performance on the Block Design and Embedded Figures Task can be explained as reduced processing of the similarities that are held between stimuli and situations. For example, in the Embedded Figures Task, the target contains some elements in common with the overall picture and features that define it. Hence, finding the target among the other patterns will be easier if the differences are more salient.

The hypothesis that individuals with autism process unique features of stimuli relatively well and the common features poorly, gives rise to two complementary predictions. First, they should be better at difficult discrimination tasks in which the stimuli to be discriminated hold many elements in common and very few unique elements. Secondly, they should be poorer at tasks requiring the categorization of two sets of stimuli. This is because, according to Plaisted's theory, individuals with autism are better at processing the difference between categories than shared category features.

Support for the first prediction comes from a perceptual learning task (Plaisted, O'Riordan, \& Baron-Cohen, 1998a) and a conjunctive visual search task (Plaisted, O'Riordan, \& Baron-Cohen, 1998b). In the perceptual learning task a neurotypical adult group showed the perceptual learning effect: they were better at discriminating between familiar than novel stimuli. The autistic adult group, however, did not show the perceptual learning effect and performed significantly better on the novel discrimination problem compared with the normal adults.

In the conjunctive search task, participants had to find a target stimulus (e.g., a red X) amongst two kinds of distracter stimuli which all shared one feature with the target (e.g., red Ts and Green Xs). Hence, the target stands out because of its combination of features; in order to find the target, participants have to be able to integrate the features. WCC theory predicts that participants with autism should be impaired on this task if they process the visual array in piecemeal and non-integrative ways, and hence should be slower at finding the target. However, the opposite was found: participants with autism were faster than neurotypicals as predicted by Reduced Generalization theory.

In support of the second prediction, that participants with autism should be poorer at a task that requires categorization of two sets of stimuli. Plaisted, O'Riordan, Aitken, and Killcross (submitted for publication) found that autistic individuals showed a deficit in 
initial category learning. Moreover, they found a reduced effect of categorising according to the prototypes, that participants could induce from exposure to examples despite never having seen them before.

One of the strengths of the theory of Reduced Generalisation is that it explains a feature of autistic learning that previously was hard to pin down theoretically: individuals with autism often have difficulty generalising newly learned behaviour to a novel environment (Mirenda \& Donnellan, 1987). This is because, according to the theory of Reduced Generalisation, an individual with autism's concepts are narrower and have sharper and more clearly delineated boundaries. Thus, in order to facilitate generalising processes, practitioners may be inclined to change the environment more gradually, to 'move in stages', by progressing through graded contexts.

\section{Hierarchization}

Mottron and Burack (2001; Mottron et al., 2006) offer an alternative account to WCC. Their staring point rests with the finding that individuals with autism process hierarchical stimuli differently than individuals without autism, in a way that cannot easily be explained by WCC theory (Mottron \& Belleville, 1993). The stimuli in question were devised by Navon (1977) and have Stroop-like properties. For example, imagine a letter H composed of small letter Ss. In this case, the elements are incongruous with the global form of the figure. Navon discovered an asymmetrical Stroop effect in that participants were slower to respond when the target was the small letter (Ss), if the global form was incongruent $(\mathrm{H})$ than if it was congruent (S); when the target was the larger letter, response time was not affected by the incongruity of the smaller letter. In other words, participants experienced interference from the global to the local, but not the reverse. This is known as global precedence (see Kimchi, 1992, for a review) or global advantage in that the global analysis takes precedence over local analysis. Mottron and Belleville (1993) recognized the value of hierarchical stimuli for testing predictions from the theory of WCC, which states that autism gives rise to detail-focused processing. Specifically, individuals with autism ought to show a reversal of the direction of interference: from local to global.

Mottron and Belleville (1993) tested their hypothesis by presenting hierarchical stimuli to an autistic savant artist (E.C.). Contrary to the theory of WCC, E.C. showed global interference similar to that in participants without autism. However, E.C. was not like comparison participants in every respect. Interestingly, he showed signs of interference from the local to the global as well as the opposite. The results led Mottron and Belleville to conclude that while individuals with autism process at the global level in a normal way, nonetheless the global does not have any special precedence over the local. They suggested that individuals with autism may fail to show the typical global precedence effect due to problems with "hierarchical organisation" in processing information. This suggestion is distinct from the theory of WCC. It says that while individuals with autism process visual information at both the global and local levels, there is an autistic impairment in handling the relationship between these two levels.

Subsequent studies have found mixed support for this suggestion. However, Plaisted, Swettenham, and Rees (1999) identified a crucial difference between the studies that support Mottron and Belleville and those that fail to do so. Mottron and Belleville's study involved a divided attention task that asked participants to report a letter at the local or global level on each trial. For instance, participants were asked to press one button if the 
letter ' $A$ ' was present (at either the local or global level) and a different button if ' $A$ ' was absent. Hence, this would require divided attention between the global and local level within each trial. Studies which failed to replicate Mottron and Belleville (e.g., Ozonoff, Strayer, McMahon, \& Filloux, 1994) presented a selective attention task, in which participants were instructed before each block of trials to attend to a particular level. For example, on being told selectively to attend to the local level, they were instructed to press one button if it was an ' $\mathrm{H}$ ' and the other if it was an ' $\mathrm{S}$ '.

To clarify matters, Plaisted et al. (1999) presented both kinds of task within a single study, and found interference from local to global in the divided attention task but not in the selective attention task. However, Rinehart, Bradshaw, Moss, Brereton, and Tonge (2000) subsequently demonstrated interference from local to global specifically in individuals with autism even on a selective attention task. This differed from the previous studies by employing numbers rather than letters as stimuli, which the authors claimed to be more sensitive to interference from local to global.

In summary, then, the bulk of evidence points towards a uniquely autistic interference from local to global, that compares with the more common asymmetrical interference from global to local. Rinehart et al. (2000) concluded that individuals with autism, "may be characterised by a deficiency in inhibiting further processing," (p. 776) even when the global figure has been identified. They proceeded to suggest that autistic peculiarities in processing hierarchical stimuli can be explained as forming part of a broader problem of inhibition, which is associated with executive dysfunction (e.g., Hughes \& Russell, 1993).

\section{WCC and visual attention}

The evidence presented so far suggests an autistic peculiarity in processing stimuli that can be apprehended on hierarchically different levels. However, Mann and Walker (2003) argued that studies using compound stimuli like the Block Design and Navon figures are subject to troublesome artefacts that may be responsible for some of the mixed findings. One of these, in the Navon task, is that the global form is more extended spatially than each local element. Hence, differences observed between local and global processes, and the interactions between them, might reflect issues to do with the control of the spread of visual attention.

A third more specific prediction (along with reduced generalisation and hierarchization) is that (1) people with autism have visual attention which is spatially overfocused and (2) a deficit in broadening their visual attention. That is, they may be able to direct visual attention, as typically developing individuals do, but without fluency (Allen \& Courchesne, 2001). In short, individuals with autism may have difficulty adjusting the spread of their visual attention which leads to priority in processing the local over the global in some circumstances. If this were the case then it would provide another way of understanding Plaisted et al.'s (1999) results: these results should only occur when participants with autism have to zoom-out to respond to the global aspect of a compound stimulus, as in the divided attention task (Mann \& Walker, 2003).

To test their hypothesis, Mann and Walker (2003) adapted a method of measuring the spread of visual attention devised by Mack and Rock (1998). In Mann and Walker's adaptation, variously sized two-line crosshairs were presented individually on successive trials, and participants had to decide which line in each (either the vertical or horizontal) was longest. If autism is associated with a tendency to over-focus attention, within a restricted region of space, then individuals with autism should respond to the smaller crosshairs with 
greater speed and accuracy than to the larger crosshair. If autism is also associated with a deficit in redistributing attention from a narrow focus to a wider distribution (i.e., zooming out is slow), then individuals with autism should experience difficulty responding to a large crosshair specifically when this is preceded by a small crosshair (rather than a large crosshair): the size of the first cross hair sets the parameter for the participants' spread of attention in the ensuing trial.

Mann and Walker (2003) found that participants with autism were less accurate and slower to respond to a crosshair when the immediately preceding trial presented a smaller crosshair. Mann and Walker interpreted this as evidence that individuals with autism have a deficit in broadening the spread of visual attention, in zooming out, which may explain their superior performance on the Embedded Figures Task (Jolliffe \& Baron-Cohen, 1997; Shah \& Frith, 1983) and the Block Design of the Wechsler intelligence scales (e.g., Shah \& Frith, 1993). Mann and Walker argued that this is a different explanation from WCC, in that it does not state that individuals with autism lack the capacity to integrate local elements to derive global form, only that they find it difficult to do this when the spread of their attention has to be broadened.

However, evidence from a study in 'boundary extension' suggests there could be a problem with Mann and Walker's (2003) account. Boundary extension is a phenomenon associated with participants' systematic distortion in their memory for a photographed scene. Specifically, when recalling or re-creating the photographed scene, participants characteristically include material that was outside the photograph's boundary at the time of initial encoding, apparently by way of extrapolation. Chapman, Ropar, Mitchell, and Ackroyd (2005) hypothesised that if participants with autism had a narrowing attentional focus, as suggested by Mann and Walker, this would interfere with their extrapolation of information that lay outside the boundary; indeed, they predicted boundary restriction in autism. Contrary to the hypothesis, boys with AS showed boundary extension precisely to the same extent as comparison participants, which they interpreted as being incompatible with Mann and Walker's theory of narrowing attentional focus.

\section{Verbal-semantic coherence}

WCC theory has another positive feature in that it extends to explain higher level/conceptual abilities (e.g., language). For example, Frith and Snowling (1983) used homographs (words with one spelling, but two pronunciations and two meanings, e.g., the metal lead and a dog's lead) to see if participants with autism use the preceding sentence to work out the meaning and use the correct pronunciation. Numerous studies (Frith \& Snowling, 1983; Happé, 1997; Jolliffe \& Baron-Cohen, 1999b; López \& Leekam, 2003; Snowling \& Frith, 1986) found that individuals with autism failed to use the correct pronunciation and, thus, presumably did not use the preceding sentence to determine correct pronunciation. This suggests they might be reading prose as a series of unconnected lists without making the appropriate associations and 'reading between-the-lines'. Such skills are needed for understanding communicational intention beyond the surface structure of language, and arguably this expression of WCC may explain some of the social difficulties seen in autism.

López and Leekam (2003) argued that being able to detect WCC in participants with autism depends on whether the task is verbal and/or visual. Using both visual and verbal tasks in their study, López and Leekam replicated Frith and Snowling's (1983) homograph test but found no evidence for WCC in their visual tasks. Hence, López and Leekam argue 
that WCC is not a general deficit in autism, but is specific to complex verbal stimuli, especially sentences that rely on context for disambiguating meaning.

\section{Can WCC phenomena be explained in terms of impaired EF?}

Does bias for local processing result from problems with retaining information in working memory? Moreover, is WCC a style of processing which results from cognitive inflexibility - a difficulty in shifting from local to global? If so, then perhaps WCC stems from executive dysfunction. To investigate this possibility, Booth, Charlton, Hughes, and Happé (2003) compared performance on a drawing task, which required the EF element of planning and central coherence, between boys with an autistic disorder, boys with ADHD and boys who were developing typically. They concluded that WCC does not reduce to EF because both clinical groups showed problems of planning, but only the group with autistic disorder showed evidence of WCC. Therefore, WCC seems to be independent of executive dysfunction in autism.

CCC theory (CCC, Frye et al., 1995; Zelazo \& Frye, 1997) suggests that individuals with autism have problems formulating and using higher-order rules, and instead rely on relatively local, unintegrated rule systems (see EF Section). If this is indeed the case with autism, then it could account to for some of the characteristics of WCC, such as difficulty handling hierarchical relations between global and local levels, processing things in piecemeal fashion and cognitive inflexibility resulting in a narrowing of concepts. However, no empirical work to date has been done to investigate this.

Arguably, another way to investigate the relation between WCC and EF is to explore whether individuals with acquired executive dysfunction (i.e., Dsyexecutive syndrome) show similar patterns of performance to those with autism on various WCC tasks. To date this has not been done.

\section{Is Central Coherence a unitary construct?}

Although the relation between $\mathrm{CC}$ and EF has not yet been investigated in individuals with acquired executive dysfunction, researchers have started to investigate the relation in neurotypical children. Pellicano, Maybery, and Durkin (2005) conducted a correlational study in which children were given a battery of developmentally appropriate CC, EF and theory of mind tasks. Factor analysis revealed that CC consisted of two constructs rather than one. Furthermore, WCC was not associated with poor theory of mind (contrary to results reported by Jarrold, Butler, Cottington, \& Jimenez, 2000), but EF (especially planning abilities) was related with one (but not both) of the CC constructs - namely, visuospatial constructional ability.

Pellicano et al. (2006) took their research a stage further by investigating the relation between WCC (specifically at the visuopatial level), EF and theory of mind in children with autism. These researchers administered a large battery of tasks tapping into all three constructs and found that children with autism could be differentiated from a neurotypical comparison group by the measures of WCC they employed. However, when the data were analysed at an individual level, Pellicano et al. did not find a consistent relation between the CC measures. They concluded that CC does not appear to be a unitary cognitive style but rather is fragmented into many components; this seems to be at odds with the idea of a general and all-encompassing central coherence continuum. 
Not only has the validity of CC been called in question following investigations into visuospatial abilities (as above), it has also come into question following studies of verbal semantic abilities. Norbury (2005) investigated the comprehension of lexical ambiguity in individuals with autism, comparing those with and without co-morbid (co-occurring) language impairment. The results suggested that problems in disambiguating meaning (requiring central coherence) are not universal in autism; rather they were found only in individuals with autism who also had core linguistic difficulties. This suggests that WCC may not be universal in the autistic population. Additionally, it seems that verbal semantic coherence is related with language impairment (and so perhaps not uniquely with autism).

\section{WCC theory as it stands now}

The original WCC hypothesis was perhaps very general, but over time it has evolved and become better specified. The negative and mixed results from many studies have, in this way, helped to delineate the boundaries of the theory's scope of explanation. Frith's (1989) original idea has been challenged in three ways and the theory has evolved (in a very different way to the other two theories) to take these into account. Firstly, Frith's conception of WCC as a deficit in global processing has been recast, instead, as superior local processing. Second, the WCC hypothesis has changed in such a way that it does not consider people with autism to either have a deficit or dysfunction (again unlike the two other cognitive theories), rather WCC is considered a cognitive style (Happé, 1999). Importantly, these styles are biases: individuals with autism may be biased to attend to detail, but through effort they may be able to extract overall meaning. Third, the explanatory power of WCC theory has changed: the theory no longer seeks to explain all aspects of autism, but rather is viewed as one part of cognition in autism (Happé \& Frith, 2006). This accords with the idea of autism being a multiple deficit.

\section{Multiple-deficit accounts}

Multiple-deficit accounts lie at the opposite end of the theoretical continuum to accounts which propose that autism can be explained as a specific deficit, such as impaired theory of mind. In recognition of the value of a multiple deficit approach, Baron-Cohen and Swettenham (1997) argue for the creation of subgroups in autism (cf. Joseph, TagerFlusberg, \& Lord, 2002), proposing that autism is in fact a complex of cognitive disorders: impaired theory of mind, WCC and executive dysfunction. They argue that autistic individuals can be affected differently in these three, possibly independent, domains. The first hard evidence for a multiple deficit account comes from Pellicano et al. (2006) who found that once age, verbal ability and non verbal ability were partialled out, the domains of theory of mind, EF and CC seemed unrelated to each other.

Multiple-deficit accounts do not assume a direct hierarchical association between various cognitive characteristics. Moreover, multiple-deficit accounts are intrinsically alluring, given the heterogeneity of possible neurological abnormality associated with autism (Bishop, 1993). Additionally, multiple-deficit accounts have implications for treatment, in that what may be effective in people affected in one domain, may be ineffective for people who have a deficit in another domain (Teunisse, Cools, van Spaendonck, Aerts, \& Berger, 2001). Furthermore, the presence of autistic individuals with different cognitive deficits/ 
styles, in the same cohort, may be a reason behind the often conflicting results seen in both basic research and intervention studies. Given the 'à la carte' menu style diagnostic system which results in the within-category heterogeneity of autism (Charman \& Swettenham, 2001), multiple-deficit accounts may prove to be useful.

Even if autism consists of multiple deficits, there may be clinical reasons for not wanting to sub-classify the disorder. The inclusion of Asperger syndrome as a diagnostic category has arguably confused matters and now the term autistic spectrum disorder (ASD) or autistic disorders is used as an all-encompassing term of anyone located on the spectrum. It may be that the term 'autism' will be reclaimed to mean an autistic spectrum disorder, sooner rather than later. Anyhow, any further sub-classification increases the risk of having categories such as low-functioning Asperger, medium-functioning Asperger, high-functioning Asperger and so on, and this fragmentation would potentially weaken the status of autism as a spectrum disorder.

One way to get around this confusion, at least experimentally, is to devise methodologies and use statistical techniques that allow the heterogeneity of autism to be taken into account in group studies. Another approach would be to focus on single case studies as in savant research or cognitive neuropsychology.

\section{Autism as a distinct entity? The borderlands of autism and other disorders}

It may be that even a new theory of autism cannot explain all the different aspects of the disorder because of the many 'types' of autism. That is, individuals with the same diagnosis may develop the same core symptoms of autism from different aetiologies. Because autism is a syndrome, a collection of symptoms, this leaves the label open for a broad range of individuals to have the same basic characteristics. The fact that there are some similarities between individuals with acquired frontal lobe head injury and autism, suggests there may even be an acquired route into autistic-like problems.

The results from recent studies suggest that different developmental disorders may be overlapping, with less clear boundaries separating them. In looking at the borderlands of autistic disorder and Specific Language Impairment (SLI), Bishop and Norbury (2002) tested the claim that all children with Pragmatic Language Impairment (PLI) would meet diagnostic criteria for autism. Standardised diagnostic measures of autism were used to assess children with PLI and children with more typical specific language impairments (SLI-T). The researchers found that a small proportion of children with PLI did meet the criteria for autism, but many did not. Bishop and Norbury argue that although the presence of PLI should prompt clinicians to investigate the possibility of autism, it is incorrect to assume that all children with pragmatic difficulties are autistic. Results like these may eventually lead to a new way of thinking about diagnosis that moves away from systems based on à la carte menu-style heuristics (e.g., Beglinger \& Smith, 2001).

Furthermore, Bishop (1989) argues that the blurred boundaries of autism are not just a consequence of the subjective and elusive nature of its symptoms. Instead it may be that autism is actually a disorder without clear boundaries (Green et al., 2002). Green et al. (2002) state that this fuzziness could equally be applied to many developmental disorders and may be viewed by some 'as a reflection of the supposed wooliness of psychology...or as an indication that developmental disorders cannot be proper diseases' (Rutter, 1998, p. 12). According to Rutter, however, such assumptions are misguided because 'even single gene Mendelian disorders show amazing variability' (Rutter, 1998, p. 12). Presumably, because 
autism may involve multiple genes (up to 24, Persico \& Bourgeron, 2006; between 2 and 10, Pickles et al., 1995), this increases the likelihood of variability and in turn makes the disorder even harder to delineate. Difficulties in knowing where one disorder ends and another begins may simply reflect the reality of developmental disorders. This need not be a problem, however, provided that the heterogeneity of individuals is taken into account in the experimental method and/or analysis, along with multiple measures of different facets of ability.

\section{Future directions}

The priorities for futures directions in the psychological study of autism are (1) to detail the actual course of development in autism prospectively. This is already being done (e.g., Berger, Aerts, van Spaendonck, Cools, \& Teunisse, 2003; Charman, 2003; Charman et al., 2005; Sigman \& Ruskin, 1999) largely thanks to early screening measures like the Checklist for Autism in Toddlers (CHAT, Baird et al., 2000) which increase the chance of an early detection of autism; (2) to compare and contrast children and adults with brain injuries with individuals with developmental disorders; (3) to advance beyond the current group design methodologies, which may be inappropriate considering the heterogeneity of autism; single case, or hybrids of single case and group studies may be preferable (see Rajendran, Mitchell, \& Rickards, 2005); (4) to define more clearly the boundaries between autism and other disorders so that aspects of autism which are not included in the diagnosis can be specified. This would allow the field to move away from the circularity of defining a disorder, by certain criteria, and then validating it by those very same criteria.

The recruitment of participants with clinical disorders that share some of the characteristics of autism will help with respect to point 4 (e.g. ADHD, Tourette syndrome, PLI). The inclusion of participants with a learning disability (mental retardation) or Down syndrome, to rule out intellectual impairment as a reason for differential performance is well established. Recently, designs with other clinical comparison groups, which share one or two of the triadic features of autism, are becoming more common. For example, Bishop and Norbury (2005a, 2005b) found that a group of children with PLI and a group with autism both had problems with two aspects of executive function: generativity (Turner, 1999) and response inhibition.

Recruiting different groups, who share features of the autistic phenotype, helps to determine whether phenomena like inhibition are unique to autism, unique to PLI or general to both disorders. From Bishop and Norbury's (2005a, 2005b) results there seems to be a relation between executive ability and language that is independent of social problems and restricted interests or behaviours, but related with the third diagnostic axis: communication impairments. Norbury (2005) has recently advanced this methodology by comparing autistic individuals with and without co-morbid language impairment, in order to tease apart the relative impact of language disorder and autism. Such studies in which participants with autism are allocated a priori to different experimental groups, on the basis of their characteristics, may offer a way forward. This methodology allows an experimentally rigorous way of differentiating autism from other disorders.

In another study, Rajendran et al. (2005) recruited individuals with Tourette syndrome as the clinical comparison group because they shared the repetitive behaviours of individuals with AS, but not the other two axes of impaired communication and socialisation. The inclusion of the Tourette group revealed that problems of understanding nonliteral 
language were neither unique to autism, nor specific to the domain of mentalising, but instead seemed related to executive dysfunction. Booth et al. (2003) recruited participants with ADHD in a similar fashion, to control for problems of EF in order to determine whether central coherence and executive function were similar processes (see Burack, Iarocci, Bowler, \& Mottron, 2002, for a discussion on matching and the role of comparison groups in developmental psychopathology research).

\section{Can the three dominant theories of autism be unified?}

Each theory of autism, considered above, seems to be able to explain many of the core and peripheral aspects of the condition and, arguably, in combination their explanatory power seems to increase. As yet, however, there is no fully integrated account which manages to both describe and explain each and every characteristic of autism. An ideal theory would trace it from infancy through to adulthood and would apply to individuals with autism who have severe learning disabilities as well as those who are higher-functioning. Any new theory would additionally have to integrate the socio-linguistic, perceptual, and sensorimotor aspects of the disorder. It would additionally need to encompass the disordered movement aspect of autism (see Green et al., 2002, for a summary of motor problems associated with autism). As yet there is no single theory which seamlessly integrates all these strands. If autism is a distinct disorder, then a useful theory would make predictions about the behaviour of everyone so diagnosed.

Autism is a non-unitary disorder, however, and the cognitive theories themselves are arguably composed of non-unitary constructs (e.g., belief attribution requires verbal and executive abilities, in addition to metarepresentational ability). Given this situation, theoreticians may have to reign in any grand claims about accounts that seek to explain autism in its entirety. Instead, they might have to consider the specific profile of an individual in order to make predictions. Such a stance would have implications for interventions and treatments: a 'one treatment fits all' approach is likely to produce mixed results given the many profiles of autism and the differing developmental trajectories individuals may follow.

This cognitively based theoretical conclusion is also supported by recent behavioural genetic data. Happé, Ronald, and Plomin (2006) argue that no single deficit is likely to explain the core triadic symptoms of autism because the less extreme forms of these behaviours are inherited almost entirely independently of each other within the general population. These researchers' population study, involving over 3000 twin pairs, elegantly circumvents any diagnostic issues by focusing on the general rather than autistic population. In essence, Happé et al. (2006) discovered only very modest correlations between socialisation, communication and repetitive behaviours/restricted interest behaviours; thereby suggesting that each element of the triad should be studied as a distinct entity. This in turn suggests there is little point in searching for a single cause resulting in the triadic phenotype seen in autism, because the elements of the triad do not seem to associate with each other.

In conclusion, mutliple-deficit accounts (e.g., Baron-Cohen \& Swettenham, 1997) may be the only ones that cover the diversity of autism, but such theories do not posit a core cognitive deficit that is responsible for the broad range of autistic symptomatology. Any integrative theory will need to engage with psychology as a whole in moving beyond the cognitive époque, to a new era, allowing developmental disorders to be viewed in a different way. 


\section{Summary and future directions}

In terms of history, theories of autism have arguably been barometers of psychological trends. They have tended to follow the theoretical zeitgeist of their times: from psychoanalytic theory, to behaviourism and then into cognitive models. As such, any theory of autism should be viewed within the context of its own time, in order to give a historical perspective. Additionally, autism research has been a crossroads and meeting point for researchers, both within and outside psychology, and from disparate backgrounds: neurologists, psychiatrists, psychologists, biologists and philosophers. For example, the discipline of molecular biology has recently become part of autism research, arising from the search for the genetic causes of the disorder and their organic and psychological counterparts.

In terms of psychology, autism can be investigated on cognitive, perceptual, developmental, social, linguistic and other levels. Autism research has already moved in a neuropsychological direction: mapping cognition onto brain function and, thus, it is still providing us with a window into neurotypicality. Hence, in the quest to understand and help people with this enigmatic disorder we gain an insight into many areas of typical psychological functioning, along with an appreciation of the complexity and the multidimensionality of human development in general.

Although it may be argued that cognitive theories may be outmoded in their ability to completely explain such a heterogeneous disorder as autism, they nevertheless represent framework(s) of choice for many researchers and clinicians. Hence, their influence is likely to remain for sometime to come. Table 1 summarises the findings of this review with respect to the criteria of specificity, uniqueness and universality, suggesting that a multiple deficit account is the one position that is most parsimonious with these findings. Accordingly, more research, like that of Pellicano et al. (2006), is required to support empirically the multiple deficit account. Nevertheless, the three cognitive theories may continue to evolve, and these changes will probably influence their explanatory power. One criticism of these theories is that they do not take a developmental approach but seem content to account for static cognitive impairments or styles in autism. A developmental and dynamic account is one direction in which the theories might develop.

The way in which we think of people with autism may also change. For example, autism may come to be thought of as a neurodevelopmental condition, rather than a neurodevelopmental disorder, as 'pure' autism becomes the norm (see Baron-Cohen, 2000 and Gernsbacher, Dawson, \& Mottron, 2006 for debates). This is because the proportion of autistic individuals with an associated learning disability has changed considerably, so that the number of people at the non-learning disabled end of the spectrum now significantly outnumber those whose IQs are under 70. The former belief that at least $70 \%$ of children with autism also have a learning disability (Rutter \& Schopler, 1987) has now been supplanted by a claim that at least 75\% have IQs in the normal range (MRC, 2001).

Any change in understanding autism as a condition than a disorder would mean that laws, policies and service provision might have to be recast for people who are different, rather than people who have a disability. As yet, there is no unified political movement for people with autism, but in time people with autism may become a vocal group in much the same way was those who are Deaf. This may be accelerated if, as a recent study suggests, as many as 1 in 100 children have some form of ASD (Baird et al., 2006). Additionally, an increase in autism to this magnitude will put pressure on services, and consequently on researchers to come up with interventions that work and theories that can be used in practice. 
Table 1

Summary of the review with respect the criteria of specificity, uniqueness and universality, using key and review articles

\begin{tabular}{|c|c|c|c|c|}
\hline & Paper type & Specificity & Uniqueness & Universality \\
\hline \multicolumn{5}{|l|}{ Reference (ToM) } \\
\hline Baron-Cohen et al. (1985) & Experiment & Not applicable & $\begin{array}{l}\text { Eighty-six percent of Children with } \\
\text { Down syndrome passed a test of first- } \\
\text { order belief attribution }\end{array}$ & $\begin{array}{l}\text { Eighty percent children with autism } \\
\text { (CWA) failed a test of first-order } \\
\text { belief attribution }\end{array}$ \\
\hline Baron-Cohen et al. (1986) & Experiment & $\begin{array}{l}\text { CWA perform poorly on mentalistic } \\
\text { type stories, but not in mechanical or } \\
\text { behavioural stories }\end{array}$ & $\begin{array}{l}\text { Children with Down syndrome } \\
\text { performed poorly (though above } \\
\text { chance) on all three stories types. } \\
\text { Notably, they performed significantly } \\
\text { better than the autism group in the } \\
\text { mentalistic story condition }\end{array}$ & Not applicable \\
\hline Baron-Cohen (1989) & Experiment & Not applicable & $\begin{array}{l}\text { Sixty percent of the children with } \\
\text { Down syndrome passed a test of } \\
\text { second-order belief attribution }\end{array}$ & $\begin{array}{l}\text { One hundred percent of children with } \\
\text { autism failed a test of second-order } \\
\text { belief attribution }\end{array}$ \\
\hline Ozonoff et al. (1991a) & Experiment & Not applicable & $\begin{array}{l}\text { No difference between CWA and a } \\
\text { clinical comparison group (comprised } \\
\text { of children with dyslexia, learning/ } \\
\text { intellectual disabilities and ADHD) } \\
\text { on mentalistic type stories, but the } \\
\text { CWA performed more poorly on } \\
\text { mechanical and behavioural stories }\end{array}$ & Not applicable \\
\hline Ozonoff et al. (1991b) & Experiment & Not applicable & Not applicable & $\begin{array}{l}\text { Sixty-nine and one hundred percent of } \\
\text { the HFA group performed below the } \\
\text { comparison group mean on the first- } \\
\text { order theory of mind and second- } \\
\text { order theory of mind composite scores } \\
\text { respectively. }\end{array}$ \\
\hline Bowler (1992) & Experiment & Not applicable & $\begin{array}{l}\text { Seventy-three percent adults with } \\
\text { Schizophrenia passed first-order test } \\
\text { of belief attribution. Sixty-seven } \\
\text { percent of adults with Schizophrenia } \\
\text { passed a test of second-order test of } \\
\text { belief attribution }\end{array}$ & $\begin{array}{l}\text { Ninety-three percent adults with AS } \\
\text { passed a first-order test of belief } \\
\text { attribution. Seventy-three percent of } \\
\text { adults with AS passed a test of } \\
\text { second-order belief attribution, but } \\
\text { differed in their ability to justify their } \\
\text { answers. }\end{array}$ \\
\hline
\end{tabular}




\begin{tabular}{|c|c|c|}
\hline & Paper type & Specificity \\
\hline Happé, 1995 & Review & $\begin{array}{l}\text { Verbal ability mediates ToM. Typically } \\
\text { developing children have a } 50 \% \text { of } \\
\text { passing first order belief attribution } \\
\text { tasks at } 4 \text {-year-old. CWA have } 50 \% \text { if } \\
\text { they have a VMA of } 9 \text { years and } \\
2 \text { months. Success in CWA is virtually } \\
\text { guaranteed beyond a VMA of } 12\end{array}$ \\
\hline Zelazo et al. (1996) & Experiment & $\begin{array}{l}\text { Domain general process of rule } \\
\text { embedding underlies ToM } \\
\text { performance in both children with } \\
\text { autism and Down syndrome }\end{array}$ \\
\hline Minter et al. (1998) & Experiment & Not applicable \\
\hline Yirmiya et al. (1998) & Review & Not applicable \\
\hline Perner and Lang (1999) & Review & $\begin{array}{l}\text { Describes the relations between ToM } \\
\& \text { EF in a number of studies of mainly } \\
\text { typically developing children, and the } \\
\text { ways in which ToM \& EF might be } \\
\text { related }\end{array}$ \\
\hline $\begin{array}{l}\text { Peterson and Siegal } \\
\quad(2000)\end{array}$ & Review & Not applicable \\
\hline Woolfe et al. (2002) & Experiment & Not applicable \\
\hline Apperly et al. (2005) & Review & $\begin{array}{l}\text { Evidence from brain injured patients } \\
\text { suggests no evidence for the domain- } \\
\text { specificity for ToM (as measured by } \\
\text { belief attribution) }\end{array}$ \\
\hline Pellicano et al. (2006) & Experiment & See below \\
\hline
\end{tabular}

Uniqueness

Children with intellectual/learning

disability ( $58 \%$ pass rate) show similar

levels of passing first-order belief

attribution tasks as typically

developing children (56\% pass rate)

Children with Down syndrome were liable to fail false belief tasks beyond the age of 4

Child who are blind were liable to fail false belief tasks beyond the age of 4

Children with intellectual/learning disabilities (including children with Down syndrome) showed ToM

deficits - though they were less severe than in children with autism. The severity of impairment is unique to autism rather than impairment itself Not applicable

Children who are late signing deaf fail false belief tasks beyond the age of 4

Children who are late signing deaf fail false belief tasks beyond the age of 4 Not applicable

Not applicable
Not applicable

Not applicable

Not applicable

Not applicable

Universality

Eighty percent of children with autism

tests of first-order belief

attribution

Not applicable

Not applicable

Not applicable

Not applicable

Poor performance on false belief accounted for $68 \%$ of children with autism. 
Pellicano (in press)

Reference (EF)

Ozonoff et al. (1991a)

Ozonoff et al. (1991b)

Hill (2004a)

Hill and Bird (2006)

Pellicano et al. (2006)

Reference (WCC)

Happé (1999)

Booth et al. (2003)

Happé and Frith (2006)
Experimen

Not applicable

Experiment Not applicable

Experiment Not applicable

Some children with autism failed

ToM tasks, but performed well on EF

tasks, while no children had the

opposite profile

Review Not applicable

Experiment Not applicable

\& Review

Experiment

When age, verbal ability and non verbal ability was partialled out, EF,

ToM and CC were unrelated to each other in children with autism

Review Studies show that WCC and ToM seem independent. Even individuals who pass ToM tests show WCC in homograph and block design

Experiment WCC found to be dissociable from EF.

EF may be required in shifting from local to global processing and so is compatible with WCC theory, even though WCC is not the same as EF
Not applicable

Not applicable

Not applicable

Not applicable

Not applicable

Not applicable

In a drawing task, children with

ADHD showed problems of EF

(planning) but not WCC

Not applicable
Not applicable

Ninety-six percent of the autistic group performed less well on EF tests

than the control group mean

One hundred percent of the HFA group

performed below the comparison group mean on the EF composite. Ninety percent of the AS group performed below the comparison group mean on the EF composite

A review of EF studies show inconsistency in both within and between studies

A battery of tests revealed problems in the EFs of response initiation and intentionality in a group with AS $50 \%$ of children with autism sample had EF problems

Not applicable

Not applicable 
Leaving aside the issue of condition or disorder, there is little doubt that the study of autism has highlighted the complex nature of development in general and that developmental trajectories are not fated from diagnosis. Autism may, in fact, be a good example of both equifinality (where there is more than one developmental pathway to a given outcome) and multifinality (where early experiences do not necessarily result in the same outcome). These two concepts were first coined by Cicchetti and Rogosch (1996), and in a recent article Pennington (2006) goes further by ascribing a multiple cognitive deficit model (rather than a single deficit) for understanding development disorders in general, including dyslexia, ADHD and autism. This is because a single cognitive deficit model cannot easily account for co-morbidity of developmental disorders, especially with respect to their often high levels of genetic and cognitive overlap (see Pennington, 2006, for a detailed account of his model). The issue of co-morbidity is clearly seen in dyslexia and ADHD, and this is now becoming more widely recognised in autism too.

Support for multiple pathways to different behavioural phenotypes has also been argued from recent genetic work: Belmonte and Bourgeron (2006) state that researchers have historically tried to understand development disorders using a traditional cognitive neuropsychological model (Shallice, 1988), by trying to study them as if they were they were lesions, a missing locus or capacity in another-wise normal, fully developed brain in which all other factors have somehow been held constant. In disagreement, Johnson, Halit, Grice, and Karmiloff-Smith (2002) argue that this approach is inappropriate for understanding developmental disorders because it assumes that the disorder is a function of a localised module, rather than an emergent property of developmental interactions among many brain regions and functions. By looking at the similarities between the behavioural phenotype of a single gene disorder (Fragile X-syndrome) and autism, Belmonte and Bourgeron (2006) propose that complexities found within neuronal networks within even single gene disorders may enlighten us to the many possible routes in a multiple gene disorder like autism (see also Persico \& Bourgeron, 2006).

By looking at aetiology (e.g., genes), brain mechanisms, cognition and behaviour, autism research (and atypical developmental research, in general) has driven theory advancement and understanding at all these levels. Furthermore, evidence has forced researchers to look at the interplay between individual differences and qualitatively distinct conditions or disorders, to acknowledge the synthesis of the person with their condition.

\section{Acknowledgments}

This paper was written in part while the first author held an Economic and Social Research Council studentship and then an ESRC Fellowship at The University of Nottingham. The authors thank the anonymous reviewers for their suggestions and comments.

\section{References}

Allen, G., \& Courchesne, E. (2001). Attention function and dysfunction in autism. Frontiers in Bioscience, 6, D105-D119.

Anderson, S. W., Damasio, H., Jones, R. D., \& Tranel, D. (1991). Wisconsin card sorting test-performance as a measure of frontal-lobe damage. Journal of Clinical and Experimental Neuropsychology, 13(6), 909-922.

Apperly, I. A., Samson, D., \& Humphreys, G. W. (2005). Domain-specificity and theory of mind: evaluating neuropsychological evidence. Trends in Cognitive Sciences, 9(12), 572-577. 
Asperger, H. (1944). Die ‘autistischen psychopathen' im kindesalter. Archiv für Psychiatrie und Nervenkrankheiten, 177, 76-136.

Back, E., Ropar, D., \& Mitchell, P. (in press). Do the eyes have it? Inferring mental states from animated faces in autism. Child Development.

Baddeley, A., \& Wilson, B. (1988). Frontal amnesia and the dysexecutive syndrome. Brain and Cognition, 7(2), 212-230.

Baird, G., Charman, T., Baron-Cohen, S., Cox, A., Swettenham, J., Wheelwright, S., et al. (2000). A screening instrument for autism at 18 months of age: a 6-year follow-up study. Journal of the American Academy of Child and Adolescent Psychiatry, 39(6), 694-702.

Baird, G., Simonoff, E., Pickles, A., Chandler, S., Loucas, T., Meldrum, D., et al. (2006). Prevalence of disorders of the autism spectrum in a population cohort of children in south thames: the special needs and autism project (snap). Lancet, 368(9531), 210-215.

Baron-Cohen, S. (1989). The autistic child's theory of mind-a case of specific developmental delay. Journal of Child Psychology and Psychiatry and Allied Disciplines, 30(2), 285-297.

Baron-Cohen, S. (1995). Mindblindness. Cambridge MA: MIT Press.

Baron-Cohen, S. (2000). Is asperger syndrome/high-functioning autism necessarily a disability? Development And Psychopathology, 12(3), 489-500.

Baron-Cohen, S., Golan, O., Wheelwright, S., \& Hill, J.J. (2004). Mind reading: The interactive guide to emotions. London: Jessica Kingsley Limited (<www.jkp.com>).

Baron-Cohen, S., Jolliffe, T., Mortimore, C., \& Robertson, M. (1997). Another advanced test of theory of mind: evidence from very high functioning adults with autism or asperger syndrome. Journal of Child Psychology and Psychiatry and Allied Disciplines, 38(7), 813-822.

Baron-Cohen, S., Leslie, A. M., \& Frith, U. (1985). Does the autistic-child have a theory of mind. Cognition, 21(1), $37-46$.

Baron-Cohen, S., Leslie, A. M., \& Frith, U. (1986). Mechanical, behavioral and intentional understanding of picture stories in autistic-children. British Journal of Developmental Psychology, 4, 113-125.

Baron-Cohen, S., O'Riordan, M., Stone, V., Jones, R., \& Plaisted, K. (1999). Recognition of faux pas by normally developing children and children with asperger syndrome or high-functioning autism. Journal of Autism and Developmental Disorders, 29(5), 407-418.

Baron-Cohen, S., \& Swettenham, J. (1997). Theory of mind in autism: its relationship to executive function and central coherence. In D. J. Cohen \& F. R. Volkmar (Eds.), Handbook for autism and pervasive developmental disorders (pp. 880-893). New York: Wiley.

Baron-Cohen, S., Wheelwright, S., Hill, J., Raste, Y., \& Plumb, I. (2001a). The "reading the mind in the eyes" test revised version: a study with normal adults, and adults with asperger syndrome or high-functioning autism. Journal of Child Psychology and Psychiatry and Allied Disciplines, 42(2), 241-251.

Baron-Cohen, S., Wheelwright, S., Scahill, V., Lawson, J., \& Spong, A. (2001b). Are intuitive physics and intuitive psychology independent? A test with children with asperger syndrome. Journal of Developmental and Learning Disorders, 47-78(5), 47-78.

Beglinger, L. J., \& Smith, T. H. (2001). A review of subtyping in autism and proposed dimensional classification model. Journal Of Autism And Developmental Disorders, 31(4), 411-422.

Belmonte, M. K., \& Bourgeron, T. (2006). Fragile x syndrome and autism at the intersection of genetic and neural networks. Nature Neuroscience, 9(10), 1221-1225.

Bennetto, L., Pennington, B. F., \& Rogers, S. J. (1996). Intact and impaired memory functions in autism. Child Development, 67(4), 1816-1835.

Berger, H. J. C., Aerts, F., van Spaendonck, K. P. M., Cools, A. R., \& Teunisse, J. P. (2003). Central coherence and cognitive shifting in relation to social improvement in high-functioning young adults with autism. Journal of Clinical And Experimental Neuropsychology, 25(4), 502-511.

Bettleheim, B. (1967). The empty fortress: Infantile autism and the birth of the self. London: Collier-Macmillan.

Bishop, D. V. M. (1989). Autism, aspergers syndrome and semantic pragmatic disorder-where are the boundaries. British Journal of Disorders of Communication, 24(2), 107-121.

Bishop, D. V. M. (1993). Autism, executive functions and theory of mind-a neuropsychological perspective. Journal of Child Psychology and Psychiatry and Allied Disciplines, 34(3), 279-293.

Bishop, D. V. M., \& Norbury, C. F. (2002). Exploring the borderlands of autistic disorder and specific language impairment: a study using standardised diagnostic instruments. Journal of Child Psychology and Psychiatry and Allied Disciplines, 43(7), 917-929. 
Bishop, D. V. M., \& Norbury, C. F. (2005a). Executive functions in children with communication impairments, in relation to autistic symptomatology. 2. Response inhibition. Autism, 9(1), 29-43.

Bishop, D. V. M., \& Norbury, C. F. (2005b). Executive functions in children with communication impairments, in relation to autistic symptomatology. 1. Generativity. Autism, 9(1), 7-27.

Bloom, P., \& German, T. P. (2000). Two reasons to abandon the false belief task as a test of theory of mind. Cognition, 77(1), B25-B31.

Booth, R., Charlton, R., Hughes, C., \& Happé, F. (2003). Disentangling weak coherence and executive dysfunction: planning drawing in autism and attention-deficit/hyperactivity disorder. Philosophical Transactions of the Royal Society of London Series B-Biological Sciences, 358(1430), 387-392.

Bowler, D. M. (1992). Theory of mind in aspergers syndrome. Journal of Child Psychology and Psychiatry and Allied Disciplines, 33(5), 877-893.

Bowler, D. M., Matthews, N. J., \& Gardiner, J. M. (1997). Asperger's syndrome and memory: similarity to autism but not amnesia. Neuropsychologia, 35(1), 65-70.

Brosnan, M. J., Scott, F. J., Fox, S., \& Pye, J. (2004). Gestalt processing in autism: failure to process perceptual relationships and the implications for contextual understanding. Journal Of Child Psychology And Psychiatry, 45(3), 459-469.

Burack, J. A., Iarocci, G., Bowler, D., \& Mottron, L. (2002). Benefits and pitfalls in the merging of disciplines: the example of developmental psychopathology and the study of persons with autism. Development and Psychopathology, 14(2), 225-237.

Burgess, P. W., Alderman, N., Evans, J., Emslie, H., \& Wilson, B. A. (1998). The ecological validity of tests of executive function. Journal of the International Neuropsychological Society, 4(6), 547-558.

Carey, S. (1985). Conceptual change in childhood. Cambridge MA: MIT Press.

Chapman, P., Ropar, D., Mitchell, P., \& Ackroyd, K. (2005). Understanding boundary extension: normalization and extension errors in picture memory among adults and boys with and without asperger's syndrome. Visual Cognition, 12(7), 1265-1290.

Charman, T. (2003). Why is joint attention a pivotal skill in autism? Philosophical Transactions of the Royal Society of London Series B-Biological Sciences, 358(1430), 315-324.

Charman, T., \& Swettenham, J. (2001). Repetitive behaviors and social-communicative impairments in autism: implications for developmental theory and diagnosis. In J. A. Burack, T. Charman, N. Yirmiya, \& P. R. Zelazo (Eds.), The development of autism: Perspectives from theory and research (pp. 195-217). Mahwah, NJ: Lawrence Erlbaum Associates.

Charman, T., Taylor, E., Drew, A., Cockerill, H., Brown, J. A., \& Baird, G. (2005). Outcome at 7 years of children diagnosed with autism at age. 2. Predictive validity of assessments conducted at 2 and 3 years of age and pattern of symptom change over time. Journal of Child Psychology and Psychiatry, 46(5), 500-513.

Cicchetti, D., \& Rogosch, F. A. (1996). Equifinality and multifinality in developmental psychopathology. Development And Psychopathology, 8(4), 597-600.

Colvert, E., Custance, D., \& Swettenham, J. (2002). Rule-based reasoning and theory of mind in autism: a commentary on the work of Zelazo, Jacques, Burack and Frye. Infant and Child Development, 11(2), 197-200.

Denkla, M. B. (1996a). Biological correlates of learning and attention: what is relevant to learning disability and attention hyperactivity disorder? Developmental and Behavioural Paediatrics, 17, 114-119.

Denkla, M. B. (1996b). A theory and model of executive function: a neuropsychological perspective. In G. R. Lyon \& N. A. Krasnegor (Eds.), Attention, memory and executive function (pp. 263-278). Baltimore, MD: Paul H. Brookes.

Dennett, D. C. (1978). Beliefs about beliefs. Behavioural and Brain Sciences, 1, 568-570.

Eskes, G. A., Bryson, S. E., \& McCormick, T. A. (1990). Comprehension of concrete and abstract words in autistic-children. Journal of Autism and Developmental Disorders, 20(1), 61-73.

Fodor, J. A. (1992). A theory of the child's theory of mind. Cognition, 44, 283-296.

Frith, U. (1970). Studies in pattern detection in normal and autistic children. 1. Immediate recall of auditory sequences. Journal of Abnormal Psychology, 76, 413-420.

Frith, U. (1971). Spontaneous patterns produced by autistic, normal and subnormal children. In M. Rutter (Ed.), Infantile autism: Concepts, characteristics and treatment (pp. 113-133). London: Churchill Livingstone.

Frith, U. (1989). Autism: Explaining the enigma. Oxford: Blackwell.

Frith, U. (2003). Autism: Explaining the enigma (2nd ed.). Oxford: Blackwell.

Frith, U., \& Happé, F. (1994). Autism - beyond theory of mind. Cognition, 50(1-3), 115-132.

Frith, U., Happé, F., \& Siddons, F. (1994). Autism and theory of mind in everyday life. Social Development, 3, $108-124$. 
Frith, U., \& Snowling, M. (1983). Reading for meaning and reading for sound in autistic and dyslexic children. Journal of Developmental Psychology, 1, 329-342.

Frye, D., Zelazo, P. D., \& Palfai, T. (1995). Theory of mind and rule-based reasoning. Cognitive Development, $10(4), 483-527$.

Gernsbacher, M. A., Dawson, M., \& Mottron, L. (2006). Autism: common, heritable, but not harmful. Behavioral and Brain Sciences, 29(4), 413.

Gillberg, C., \& Coleman, M. (2000). The biology of the autistic syndromes (3rd ed.). London: Mac Keith.

Golan, O., \& Baron-Cohen, S. (2006). Systemizing empathy: teaching adults with asperger syndrome or highfunctioning autism to recognize complex emotions using interactive multimedia. Development and Psychopathology, 18(2), 591-617.

Golan, O., Baron-Cohen, S., Hill, J.J., \& Rutherford, M.D. (in press). The "reading the mind in the voice test-revised: a study of complex emotion recognition in adults with and without autism spectrum conditions. Journal of Autism and Developmental Disorders.

Green, D., Baird, G., Barnett, A. L., Henderson, L., Huber, J., \& Henderson, S. E. (2002). The severity and nature of motor impairment in asperger's syndrome: a comparison with specific developmental disorder of motor function. Journal of Child Psychology and Psychiatry and Allied Disciplines, 43(5), 655-668.

Hadwin, J., BaronCohen, S., Howlin, P., \& Hill, K. (1996). Can we teach children with autism to understand emotions, belief, or pretence? Development and Psychopathology, 8(2), 345-365.

Hadwin, J., BaronCohen, S., Howlin, P., \& Hill, K. (1997). Does teaching theory of mind have an effect on the ability to develop conversation in children with autism? Journal of Autism and Developmental Disorders, 27(5), 519-537.

Hala, S., \& Russell, J. (2001). Executive control within strategic deception: a window on early cognitive development? Journal of Experimental Child Psychology, 80(2), 112-141.

Happé, F., \& Frith, U. (2006). The weak coherence account: detail-focused cognitive style in autism spectrum disorders. Journal of Autism and Developmental Disorders, 36(1), 5-25.

Happé, F., Ronald, A., \& Plomin, R. (2006). Time to give up on a single explanation for autism. Nature Neuroscience, 9(10), 1218-1220.

Happé, F. (1999). Autism: cognitive deficit or cognitive style? Trends in Cognitive Sciences, 3(6), 216-222.

Happé, F. G. E. (1994). An advanced test of theory of mind - understanding of story characters thoughts and feelings by able autistic, mentally - handicapped, and normal - children and adults. Journal of Autism and Developmental Disorders, 24(2), 129-154.

Happé, F. G. E. (1995). The role of age and verbal-ability in the theory of mind task- performance of subjects with autism. Child Development, 66(3), 843-855.

Happé, F. G. E. (1996). Studying weak central coherence at low levels: children with autism do not succumb to visual illusions. A research note. Journal of Child Psychology and Psychiatry and Allied Disciplines, 37(7), 873-877.

Happé, F. G. E. (1997). Central coherence and theory of mind in autism: reading homographs in context. British Journal of Developmental Psychology, 15, 1-12.

Heaton, R. K. (1981). Wisconsin card sorting test manual. Odessa, FL: Psychology Assessment Resources.

Heider, F., \& Simmel, M. (1944). An experimental study of apparent behavior. The American Journal of Psychology, 57, 243-259.

Hermelin, B., \& O'Connor, N. (1967). Remembering of words by psychotic and subnormal children. British Journal of Psychology, 58, 213-218.

Hermelin, B., \& O'Connor, N. (1970). Psychological experiments with autistic children. Oxford: Pergamon Press.

Hill, E. L. (2004a). Evaluating the theory of executive dysfunction in autism. Developmental Review, 24(2), $189-233$.

Hill, E. L. (2004b). Executive dysfunction in autism. Trends in Cognitive Sciences, 8(1), $26-32$.

Hill, E. L., \& Bird, C. A. (2006). Executive processes in Asperger syndrome: Patterns of performance in a multiple case series. Neuropsychologia, 44(14), 2822-2835.

Hill, E. L., \& Russell, J. (2002). Action memory and self-monitoring in children with autism: self versus other. Infant and Child Development, 11(2), 159-170.

Hughes, C., \& Russell, J. (1993). Autistic children's difficulty with mental disengagement from an object-its implications for theories of autism. Developmental Psychology, 29(3), 498-510.

Jarrold, C., Butler, D. W., Cottington, E. M., \& Jimenez, F. (2000). Linking theory of mind and central coherence bias in autism and in the general population. Developmental Psychology, 36(1), 126-138.

Johnson, M. H., Halit, H., Grice, S. J., \& Karmiloff-Smith, A. (2002). Neuroimaging of typical and atypical development: a perspective from multiple levels of analysis. Development and Psychopathology, 14(3), 521-536. 
Jolliffe, T., \& Baron-Cohen, S. (1997). Are people with autism and asperger syndrome faster than normal on the embedded figures test? Journal of Child Psychology and Psychiatry and Allied Disciplines, 38(5), 527-534.

Jolliffe, T., \& Baron-Cohen, S. (1999a). The strange stories test: a replication with high-functioning adults with autism or asperger syndrome. Journal of Autism and Developmental Disorders, 29(5), 395-406.

Jolliffe, T., \& Baron-Cohen, S. (1999b). A test of central coherence theory: linguistic processing in high-functioning adults with autism or asperger syndrome: is local coherence impaired? Cognition, 71(2), 149-185.

Joseph, R. M., Tager-Flusberg, H., \& Lord, C. (2002). Cognitive profiles and social-communicative functioning in children with autism spectrum disorder. Journal of Child Psychology and Psychiatry and Allied Disciplines, 43(6), 807-821.

Kanner, L. (1943). Autistic disturbances of affective contact. Nervous Child, 2, 217-250.

Kimchi, R. (1992). Primacy of wholistic processing and global local paradigm - a critical review. Psychological Bulletin, 112(1), 24-38.

Klin, A. (2000). Attributing social meaning to ambiguous visual stimuli in higher-functioning autism and asperger syndrome: the social attribution task. Journal of Child Psychology and Psychiatry and Allied Disciplines, 41(7), 831-846.

Klin, A., Jones, W., Schultz, R., \& Volkmar, F. (2003). The enactive mind, or from actions to cognition: lessons from autism. Philosophical Transactions of the Royal Society of London Series B-Biological Sciences, 358(1430), 345-360.

Leslie, A. M., \& Thaiss, L. (1992). Domain specificity in conceptual development: neuropsychological evidence from autism. Cognition, 43, 225-251.

Levisohn, L., Cronin-Golomb, A., \& Schmahmann, J. D. (2000). Neuropsychological consequences of cerebellar tumour resection in children - cerebellar cognitive affective syndrome in a paediatric population. Brain, 123, $1041-1050$.

Liss, M., Fein, D., Allen, D., Dunn, M., Feinstein, C., Morris, R., et al. (2001). Executive functioning in highfunctioning children with autism. Journal of Child Psychology and Psychiatry and Allied Disciplines, 42(2), 261-270.

Lovaas, O. I. (1966). A program for the establishment of speech in psychotic children. In J. K. Wing (Ed.), Early childhood autism: Clinical education and social aspects. London: Pergamon Press.

Lovaas, O. I., Schaeffer, B., \& Simmons, J. Q. (1965). Building social behaviour in autistic children by the use of electric shock. Journal of Experimental Research in Personality, 1, 99-109.

Luria, A.R. (1973). The working brain: An introduction to neuropsychology (B. Haigh, Trans.). New York: Basic Books Inc.

López, B., \& Leekam, S. R. (2003). Do children with autism fail to process information in context? Journal of Child Psychology and Psychiatry and Allied Disciplines, 44(2), 285-300.

Mack, A., \& Rock, I. (1998). Inattentional blindness. Cambridge, MA: MIT Press.

Mackinlay, R., Charman, T., \& Karmiloff-Smith, A. (2006). High functioning children with autism spectrum disorder: a novel test of multitasking. Brain and Cognition, 61(1), 14-24.

Mann, T. A., \& Walker, P. (2003). Autism and a deficit in broadening the spread of visual attention. Journal of Child Psychology and Psychiatry and Allied Disciplines, 44(2), 274-284.

Mari, M., Castiello, U., Marks, D., Marraffa, C., \& Prior, M. (2003). The reach-to-grasp movement in children with autism spectrum disorder. Philosophical Transactions of the Royal Society of London Series B-Biological Sciences, 358(1430), 393-403.

Marschark, M., Green, V., Hindmarsh, G., \& Walker, S. (2000). Understanding theory of mind in children who are deaf. Journal of Child Psychology and Psychiatry and Allied Disciplines, 41(8), 1067-1073.

Milne, E., Swettenham, J., Hansen, P., Campbell, R., Jeffries, H., \& Plaisted, K. (2002). High motion coherence thresholds in children with autism. Journal of Child Psychology and Psychiatry and Allied Disciplines, 43(2), 255-263.

Minshew, N. J., Goldstein, G., \& Siegel, D. J. (1995). Speech and language in high-functioning autistic individuals. Neuropsychology, 9(2), 255-261.

Minter, M., Hobson, R. P., \& Bishop, M. (1998). Congenital visual impairment and 'theory of mind'. British Journal of Developmental Psychology, 16, 183-196.

Mirenda, P. L., \& Donnellan, A. M. (1987). Issues in curriculum development. In D. J. Cohen, A. M. Donnellan, \& R. Paul (Eds.), Handbook of autism and pervasive developmental disorders. New York: John Wiley and Sons.

Mitchell, P., \& Ropar, D. (2004). Visuo-spatial abilities in autism: a review. Infant and Child Development, 13(3), $185-198$.

Mottron, L., \& Belleville, S. (1993). A study of perceptual analysis in a high-level autistic subject with exceptional graphic abilities. Brain and Cognition, 23(2), 279-309. 
Mottron, L., \& Burack, J. (2001). Enhanced perceptual functioning in the development of autism. In J. Burack, T. Charman, N. Yirmiya, \& P. D. Zelazo (Eds.), The development of autism: Perspectives from theory and research (pp. 131-148). Mahwah, NJ: Erlbaum.

Mottron, L., Dawson, M., Soulieres, I., Hubert, B., \& Burack, J. (2006). Enhanced perceptual functioning in autism: an update, and eight principles of autistic perception. Journal of Autism and Developmental Disorders, $36(1), 27-43$.

MRC. (2001). MRC reviews of autism research: Epidemiology and causes. London: Medical Research Council.

Navon, D. (1977). Forest before trees: the precedence of global features in visual perception. Cognitive Psychology, 9, 353-383.

Norbury, C. F. (2005). Barking up the wrong tree? Lexical ambiguity resolution in children with language impairments and autistic spectrum disorders. Journal of Experimental Child Psychology, 90(2), 142-171.

Norris, G., \& Tate, R. L. (2000). The behavioural assessment of the dysexecutive syndrome (bads): ecological, concurrent and construct validity. Neuropsychological Rehabilitation, 10(1), 33-45.

Nyden, A., Gillberg, C., Hjelmquist, E., \& Heiman, M. (1999). Executive function/ attention deficits in boys with asperger syndrome attention disorder and reading/writing disorder. Autism, 3, 213-228.

O’Neill, M., \& Jones, R. S. P. (1997). Sensory-perceptual abnormalities in autism: a case for more research? Journal of Autism and Developmental Disorders, 27(3), 283-293.

Ozonoff, S. (1997). Components of executive functioning in autism and other disorders. In J. Russell (Ed.), Autism as an executive disorder. New York: Oxford University Press.

Ozonoff, S., \& Jensen, J. (1999). Brief report: specific executive function profiles in three neurodevelopmental disorders. Journal of Autism and Developmental Disorders, 29(2), 171-177.

Ozonoff, S., \& McEvoy, R. E. (1994). A longitudinal-study of executive function and theory of mind development in autism. Development and Psychopathology, 6(3), 415-431.

Ozonoff, S., Pennington, B. F., \& Rogers, S. J. (1991a). Executive function deficits in high-functioning autistic individuals - relationship to theory of mind. Journal of Child Psychology and Psychiatry and Allied Disciplines, 32(7), 1081-1105.

Ozonoff, S., Rogers, S. J., \& Pennington, B. F. (1991b). Aspergers syndrome - evidence of an empirical distinction from high-functioning autism. Journal of Child Psychology and Psychiatry and Allied Disciplines, 32(7), $1107-1122$.

Ozonoff, S., Strayer, D. L., McMahon, W. M., \& Filloux, F. (1994). Executive function abilities in autism and tourette syndrome - an information-processing approach. Journal of Child Psychology and Psychiatry and Allied Disciplines, 35(6), 1015-1032.

Pellicano, E. (in press). Links between theory of mind and executive function in young children with autism: clues to developmental primacy. Development Psychology.

Pellicano, E., Maybery, M., \& Durkin, K. (2005). Central coherence in typically developing preschoolers: does it cohere and does it relate to mindreading and executive control? Journal of Child Psychology and Psychiatry, 46(5), 533-547.

Pellicano, E., Maybery, M., Durkin, K., \& Maley, A. (2006). Multiple cognitive capabilities/deficits in children with an autism spectrum disorder: "weak" central coherence and its relationship to theory of mind and executive control. Development and Psychopathology, 18(1), 77-98.

Pennington, B. F. (2006). From single to multiple deficit models of developmental disorders. Cognition, 101(2), 385-413.

Pennington, B. F., \& Ozonoff, S. (1996). Executive functions and developmental psychopathology. Journal of Child Psychology and Psychiatry and Allied Disciplines, 37(1), 51-87.

Perner, J., Frith, U., Leslie, A. M., \& Leekam, S. R. (1989). Exploration of the autistic childs theory of mindknowledge, belief, and communication. Child Development, 60(3), 689-700.

Perner, J., \& Lang, B. (1999). Development of theory of mind and executive control. Trends in Cognitive Sciences, $3(9), 337-344$.

Perner, J., Lang, B., \& Kloo, D. (2002). Theory of mind and self-control: more than a common problem of inhibition. Child Development, 73(3), 752-767.

Perner, J., \& Wimmer, H. (1985). John thinks that mary thinks that - attribution of 2nd-order beliefs by 5 -yearold to 10-year-old children. Journal of Experimental Child Psychology, 39(3), 437-471.

Persico, A. M., \& Bourgeron, T. (2006). Searching for ways out of the autism maze: genetic, epigenetic and environmental clues. Trends In Neurosciences, 29(7), 349-358.

Peterson, C. C., \& Siegal, M. (2000). Insights into theory of mind from deafness and autism. Mind \& Language, $15(1), 123-145$. 
Peterson, D., \& Bowler, D. M. (2000). Counterfactual reasoning and false belief understanding in children with autism. Autism, 4(4), 391-405.

Pickles, A., Bolton, P., Macdonald, H., Bailey, A., Lecouteur, A., Sim, C. H., et al. (1995). Latent-class analysis of recurrence risks for complex phenotypes with selection and measurement error - a twin and family history study of autism. American Journal of Human Genetics, 57(3), 717-726.

Plaisted, K., O’Riordan, M., \& Baron-Cohen, S. (1998a). Enhanced discrimination of novel, highly similar stimuli by adults with autism during a perceptual learning task. Journal of Child Psychology and Psychiatry and Allied Disciplines, 39(5), 765-775.

Plaisted, K., O’Riordan, M., \& Baron-Cohen, S. (1998b). Enhanced visual search for a conjunctive target in autism: a research note. Journal of Child Psychology and Psychiatry and Allied Disciplines, 39(5), 777-783.

Plaisted, K., Swettenham, J., \& Rees, L. (1999). Children with autism show local precedence in a divided attention task and global precedence in a selective attention task. Journal of Child Psychology and Psychiatry and Allied Disciplines, 40(5), 733-742.

Plaisted, K. C. (2001). Reduced generalization in autism: an alternative to weak central coherence. In J. A. Burack, T. Charman, N. Yirmiya, \& P. R. Zelazo (Eds.), The development of autism: Perspectives from theory and research (pp. 149-172). Mahwah, NJ: Lawrence Erlbaum Associates.

Plaisted, K.C., O'Riordan, M.A., Aitken, M.R.F., \& Killcross, A.S. (submitted for publication). Categorisation in autism: evidence of a reduced prototype effect.

Premack, D., \& Woodruff, G. (1978). Does the chimpanzee have a theory of mind? Behavioural and Brain Sciences, 4, 515-526.

Prior, M. (1977). Psycholinguistic disabilities of autistic and retarded children. Journal of Mental Deficiency Research, 21, 37-45.

Prior, M. R. (1979). Cognitive-abilities and disabilities in infantile-autism-review. Journal of Abnormal Child Psychology, 7(4), 357-380.

Prior, M. R., Gajzago, C. C., \& Knox, D. T. (1976). Epidemiological-study of autistic and psychotic children in 4 eastern states of Australia. Australian and New Zealand Journal of Psychiatry, 10(2), 173-184.

Rajendran, G., Mitchell, P., \& Rickards, H. (2005). How do individuals with asperger syndrome respond to nonliteral language and inappropriate requests in computer-mediated communication? Journal of Autism and Developmental Disorders, 35, 187-207.

Ricks, D. M., \& Wing, L. (1976). Language, communication and the use of symbols. In L. Wing (Ed.), Early childhood autism. New York: Pergamon.

Rinehart, N. J., Bradshaw, J. L., Moss, S. A., Brereton, A. V., \& Tonge, B. J. (2000). Atypical interference of local detail on global processing in high-functioning autism and asperger's disorder. Journal of Child Psychology and Psychiatry and Allied Disciplines, 41(6), 769-778.

Rogers, S. J., \& Ozonoff, S. (2005). Annotation: What do we know about sensory dysfunction in autism? A critical review of the empirical evidence. Journal of Child Psychology and Psychiatry, 46(12), 1255-1268.

Ropar, D., \& Mitchell, P. (1999). Are individuals with autism and asperger's syndrome susceptible to visual illusions? Journal of Child Psychology and Psychiatry and Allied Disciplines, 40(8), 1283-1293.

Ropar, D., \& Mitchell, P. (2001). Susceptibility to illusions and performance on visuospatial tasks in individuals with autism. Journal of Child Psychology and Psychiatry and Allied Disciplines, 42(4), 539-549.

Rumsey, J. M., \& Hamburger, S. D. (1988). Neuropsychological findings in high-functioning men with infantileautism, residual state. Journal of Clinical and Experimental Neuropsychology, 10(2), 201-221.

Russell, J. (1996). Agency. Its role in mental development. Hove: Erlbaum.

Russell, J., Hala, S., \& Hill, E. (2003). The automated windows task: the performance of preschool children, children with autism, and children with moderate learning difficulties. Cognitive Development, 18(1), $111-137$.

Russell, J., \& Hill, E. L. (2001). Action-monitoring and intention reporting in children with autism. Journal of Child Psychology and Psychiatry and Allied Disciplines, 42(3), 317-328.

Russell, J., \& Jarrold, C. (1998). Error-correction problems in autism: evidence for a monitoring impairment? Journal of Autism and Developmental Disorders, 28(3), 177-188.

Russell, J., Mauthner, N., Sharpe, S., \& Tidswell, T. (1991). The windows task as a measure of strategic deception in preschoolers and autistic subjects. British Journal of Developmental Psychology, 9, 331-349.

Russell, P. A., Hosie, J. A., Gray, C. D., Scott, C., Hunter, N., Banks, J. S., et al. (1998). The development of theory of mind in deaf children. Journal of Child Psychology and Psychiatry and Allied Disciplines, 39(6), 903-910.

Rutherford, M. D., Baron-Cohen, S., \& Wheelwright, S. (2002). Reading the mind in the voice: a study with normal adults and adults with asperger syndrome and high functioning autism. Journal of Autism and Developmental Disorders, 32(3), 189-194. 
Rutter, M. (1998). Foreward. In J. Rispens, T. van Yperen, \& W. Yule (Eds.), Perspectives on the classification of specific developmental disorders. Dordrecht: Kluwer.

Rutter, M., \& Schopler, E. (1987). Autism and pervasive developmental disorders-concepts and diagnostic issues. Journal Of Autism And Developmental Disorders, 17(2), 159-186.

Scott, F. J., \& Baron-Cohen, S. (1996). Imagining real and unreal things: evidence of a dissociation in autism. Journal of Cognitive Neuroscience, 8(4), 371-382.

Shah, A., \& Frith, U. (1983). An islet of ability in autistic-children - a research note. Journal of Child Psychology and Psychiatry and Allied Disciplines, 24(4), 613-620.

Shah, A., \& Frith, U. (1993). Why do autistic individuals show superior performance on the block design task. Journal of Child Psychology and Psychiatry and Allied Disciplines, 34(8), 1351-1364.

Shallice, T. (1982). Specific impairments of planning. In D. E. Broadbent \& L. Weiskrantz (Eds.), The neuropsychology of cognitive function (pp. 199-209). London: The Royal Society.

Shallice, T. (1988). From neuropsychology to mental structure. New York: Cambridge University Press.

Shallice, T. (2001). 'Theory of mind' and the prefrontal cortex. Brain, 124, 247-248.

Shallice, T., \& Burgess, P. W. (1991). Deficits in strategy application following frontal-lobe damage in man. Brain, $114,727-741$.

Sigman, M., \& Ruskin, E. (1999). Continuity and change in the social competence of children with autism, Down syndrome, and developmental delays. Monographs of the Society for Research in Child Development, 64(1), 1.

Snowling, M., \& Frith, U. (1986). Comprehension in hyperlexic readers. Journal of Experimental Child Psychology, 42(3), 392-415.

Stone, V. E., Baron-Cohen, S., \& Knight, R. T. (1998). Frontal lobe contributions to theory of mind. Journal of Cognitive Neuroscience, 10(5), 640-656.

Stroop, J. R. (1935). Studies of interference in serial verbal reactions. Journal of Experimental Psychology, $18,643-662$.

Stuss, D. T., Gallup, G. G., \& Alexander, M. P. (2001). The frontal lobes are necessary for 'theory of mind'. Brain, $124,279-286$.

Tager-Flusberg, H. (1991). Semantic processing in the free-recall of autistic-children-further evidence for a cognitive deficit. British Journal of Developmental Psychology, 9, 417-430.

Teunisse, J. P., Cools, A. R., van Spaendonck, K. P. M., Aerts, F., \& Berger, H. J. C. (2001). Cognitive styles in high-functioning adolescents with autistic disorder. Journal of Autism and Developmental Disorders, 31(1), 55-66.

Tranel, D., Anderson, S. W., \& Benton, A. (1994). Development of the concept of "executive function" and its relationship to the frontal lobes. In F. Boller \& J. Grafman (Eds.), Handbook of neuropsychology (Vol. 9, pp. 125-148). Amsterdam: Elsevier.

Turner, M. A. (1999). Generating novel ideas: fluency performance in high-functioning and learning disabled individuals with autism. Journal of Child Psychology and Psychiatry and Allied Disciplines, 40(2), 189-201.

Wahl, S., \& Spada, H. (2000). Children's reasoning about intentions, beliefs and behaviour. Cognitive Science Quarterly, 1, 5-34.

Wechsler, D. (1999). Wechsler abbreviated scale of intelligence (WASI). New York: The Psychological Corporation.

Wellman, H. M. (1990). The child's theory of mind. Cambridge MA: MIT Press.

Wellman, H. M., Cross, D., \& Watson, J. (2001). Meta-analysis of theory-of-mind development: the truth about false belief. Child Development, 72(3), 655-684.

Wilson, B. A., Alderman, N., Burgess, P. W., Emslie, H. C., \& Evans, J. J. (1996). The behavioural assessment of the dysexecutive syndrome. Flempton, Bury St. Edmunds: Thames Valley Test Company.

Wimmer, H., Hogrefe, G. J., \& Perner, J. (1988). Childrens understanding of informational access as source of knowledge. Child Development, 59(2), 386-396.

Wimmer, H., \& Perner, J. (1983). Beliefs about beliefs - representation and constraining function of wrong beliefs in young childrens understanding of deception. Cognition, 13(1), 103-128.

Wing, L. (1969). The handicaps of autistic children - a comparative study. Journal of Child Psychology and Psychiatry, 10(1), 1-40.

Witkin, H. A., Oltman, P. K., Raskin, E., \& Karp, S. (1971). A manual for the embedded figures test. California: Consulting Psychologists Press.

Woolfe, T., Want, S. C., \& Siegal, M. (2002). Signposts to development: theory of mind in deaf children. Child Development, 73(3), 768-778.

Yirmiya, N., Erel, O., Shaked, M., \& Solomonica-Levi, D. (1998). Meta-analyses comparing theory of mind abilities of individuals with autism, individuals with mental retardation, and normally developing individuals. Psychological Bulletin, 124(3), 283-307. 
Zelazo, P. D., Burack, J. A., Benedetto, E., \& Frye, D. (1996). Theory of mind and rule use in individuals with down's syndrome: a test of the uniqueness and specificity claims. Journal of Child Psychology and Psychiatry and Allied Disciplines, 37(4), 479-484.

Zelazo, P. D., Burack, J. A., Boseovski, J. J., Jacques, S., \& Frye, D. (2001). A cognitive complexity and control framework for the study of autism. In J. A. Burack, T. Charman, N. Yirmiya, \& P. R. Zelazo (Eds.), The development of autism: Perspectives from theory and research (pp. 195-217). Mahwah, NJ: Lawrence Erlbaum Associates.

Zelazo, P. D., Carter, A., Reznick, J. S., \& Frye, D. (1997). Early development of executive function: a problemsolving framework. Review of General Psychology, 1, 198-226.

Zelazo, P. D., \& Frye, D. (1997). Cognitive complexity and control: a theory of the development of deliberate reasoning and intentional action. In M. Stamenov (Ed.), Language structure, discourse, and the access to consciousness. Amsterdam, Philadelphia: John Benjamins.

Zelazo, P. D., Jacques, S., Burack, J. A., \& Frye, D. (2002). The relation between theory of mind and rule use: evidence from persons with autism-spectrum disorders. Infant and Child Development, 11(2), 171-195.

Zelazo, P. D., \& Müller, U. (2002). Executive function in typical and atypical development. In U. Goswami (Ed.), Handbook of childhood cognitive development. Oxford: Blackwell. 